ARTICLE

\title{
Lure-and-kill macrophage nanoparticles alleviate the severity of experimental acute pancreatitis
}

\author{
Qiangzhe Zhang ${ }^{1}$, Julia Zhou ${ }^{1}$, Jiarong Zhou ${ }^{1}$, Ronnie H. Fang ${ }^{1}$, Weiwei Gao (i) ${ }^{1}$ \& Liangfang Zhang (iD) ${ }^{1 凶}$
}

Acute pancreatitis is a disease associated with suffering and high lethality. Although the disease mechanism is unclear, phospholipase A2 (PLA2) produced by pancreatic acinar cells is a known pathogenic trigger. Here, we show macrophage membrane-coated nanoparticles with a built-in 'lure and kill' mechanism (denoted ' $M \Phi-N P(L \& K)^{\prime}$ ) for the treatment of acute pancreatitis. $M \Phi-N P(L \& K)$ are made with polymeric cores wrapped with natural macrophage membrane doped with melittin and MJ-33. The membrane incorporated melittin and MJ-33 function as a PLA2 attractant and a PLA2 inhibitor, respectively. These molecules, together with membrane lipids, work synergistically to lure and kill PLA2 enzymes. These nanoparticles can neutralize PLA2 activity in the sera of mice and human patients with acute pancreatitis in a dose-dependent manner and suppress PLA2-induced inflammatory response accordingly. In mouse models of both mild and severe acute pancreatitis, M $\Phi-N P(L \& K)$ confer effective protection against disease-associated inflammation, tissue damage and lethality. Overall, this biomimetic nanotherapeutic strategy offers an anti-PLA2 treatment option that might be applicable to a wide range of PLA2-mediated inflammatory disorders.

\footnotetext{
${ }^{1}$ Department of Nanoengineering, Chemical Engineering Program, Moores Cancer Center, University of California San Diego, La Jolla, CA, USA.

凶email: zhang@ucsd.edu
} 
cute pancreatitis (AP) is a disease featuring the premature activation of digestive enzymes in the pancreatic acinar cells (PACs) that leads to the digestion of the pancreas itself ${ }^{1,2}$. The self-digestive condition provokes inflammation, edema, hemorrhage, and necrosis of the pancreatic tissue. Injured PACs release an array of pro-inflammatory factors, causing peripancreatic tissue destruction and distant organ damage. The primary cause of death is multisystem organ failure resulted from systemic inflammatory response syndrome or the sepsis induced by infections of necrotic tissues ${ }^{3}$. AP is the most common cause of hospitalization for gastrointestinal diseases worldwide, and the overall incidence rate continues to rise ${ }^{4}$. Although most of the cases are mild and self-limiting, about $25 \%$ of the patients develop severe $\mathrm{AP}$, and the mortality rate of this patient group reaches $30 \%{ }^{5}$. Despite concerted efforts in the past few decades, there is still no effective drug therapy to treat $\mathrm{AP}^{6}$. The principles of care remain supportive $\mathrm{e}^{7,8}$.

Phospholipase A2 (PLA2), specifically group IIA secreted PLA2 isoform, is a known pathogenic trigger of $\mathrm{AP}^{9,10}$. The release of PLA2 from the pancreatic tissue damages the cell membrane of surrounding acinar cells, producing proinflammatory signals that exacerbate the injury ${ }^{11,12}$. PLA2 secreted from both pancreatic and distant sources propagates a systemic inflammatory response leading to lifethreatening complications such as acute respiratory distress syndrome and multisystem organ failure ${ }^{13,14}$. Serum levels of PLA2 correlate with the disease severity of AP patients and have been used to assess the diagnosis and prognosis of the disease ${ }^{15}$. Inhibition of PLA2 was shown to significantly decrease the activity of digestive enzymes and reduce tissue damages in $\mathrm{AP}^{16,17}$. Despite the potential, effective PLA2 inhibitors suitable for AP treatment remain unavailable due to the lack of specificity, inherent toxicity, and poor pharmacokinetic profiles ${ }^{18,19}$.

The unmet needs in AP treatment motivate us to develop nanoparticles with natural cell membrane coating for safe and effective PLA2 inhibition ${ }^{20}$. The membrane coating allows nanoparticles to exploit cellular membrane properties and intercept harmful chemical agents, toxins, enzymes, and viruses for biodetoxification ${ }^{21-24}$. In the pathophysiology of AP, macrophage is an essential target of PLA2 to upregulate pro-inflammatory mediators and altered cytokine reactions ${ }^{25}$. Therefore, we select macrophage $(M \Phi)$ membrane as coating materials to attract PLA2 away from the intended host cell target (Fig. 1a). We further dope the membrane with melittin, a short peptide that can lure PLA2 to attack the membrane ${ }^{23,26}$. Meanwhile, to overcome the sacrificial nature of a simple macrophage decoy, we insert MJ-33, a lipid-like PLA2-specific inhibitor into the membrane. The membrane embedment suppresses the toxicity of the inhibitor molecules otherwise unsafe for AP treatment. Upon PLA2 attack, the inhibitors are exposed and will bind and kill PLA2. With such a design, the nanoparticles (denoted 'MФ-NP $(\mathrm{L} \& \mathrm{~K})$ ') leverage macrophage membrane functions and orchestrate a 'lure and kill' mechanism for safe and responsive inhibition of PLA2.

In this work, we report MФ-NP(L\&K) formulation according to the above design principles and test therapeutic efficacy in mouse models of AP. We show that the nanoparticle formulation eliminates the toxicity associated with free melittin and MJ-33. In vitro, we demonstrate that MФ-NP(L\&K) suppresses PLA2 activity in sera of mice and humans of AP. In vivo, by using mouse models of both mild and severe AP, we show that MФ-NP $(\mathrm{L} \& \mathrm{~K})$ can effectively protect the pancreas and reduce disease severity. Overall, $\mathrm{M} \Phi-\mathrm{NP}(\mathrm{L} \& \mathrm{~K})$ are a unique biomimetic nanoparticle platform for effective and safe PLA2 inhibition with the potential for treating AP and other PLA2-mediated diseases.

\section{Results and discussion}

Nanoparticle preparation and characterization. To synthesize $M \Phi-N P(L \& K)$, the cell membrane was first derived from macrophages ${ }^{27}$. Then MJ-33 was incorporated into the cell membrane through sonication (Supplementary Fig. 1). The membrane was subsequently coated onto poly(lactic-co-glycolic acid) (PLGA) cores to form MJ-incorporated macrophage membrane-coated nanoparticles (denoted 'MФ-NP(MJ)'). Then, the suspension of MФ-NP(MJ) was added with melittin, which spontaneously inserted into the membrane of the nanoparticles, leading to the final $M \Phi-\mathrm{NP}(\mathrm{L} \& \mathrm{~K})$ formulation ${ }^{22}$. During the formulation, increasing MJ-33 input caused a higher inhibition of PLA2, but the effect plateaued at an input of $16 \mathrm{wt} \%$ (Fig. 1b). The incorporation of MJ-33 into MФ-NP(MJ) and MФ-NP(L\&K) was confirmed by using mass spectrometry (MS). Characteristic molecular ion peak was identified at $\mathrm{m} / \mathrm{z}=491.3$, which was in agreement with the theoretical molecular weight of MJ-33, indicating successful loading of MJ-33 into the nanoparticle formulations (Fig. 1c). Using a calibration curve constructed from MJ-33 standards, an MJ-33 input of $16 \mathrm{wt} \%$ was calculated to achieve a loading yield of $9.4 \mathrm{wt} \%$, which was used for all subsequent MФ-NP(MJ) formulation (Supplementary Fig. 2). Similarly, increasing melittin input also led to an increase of PLA2 inhibition (Fig. 1d). In this case, a plateau appeared at a $4 \mathrm{wt} \%$ input, equivalent to a $3.9 \mathrm{wt} \%$ melittin loading yield, calculated by quantifying the remaining melittin after incubation with MФ-NP (MJ) (Fig. 1e and Supplementary Fig. 3). This input was used in all subsequent MФ-NP(L\&K) formulations. When examined with dynamic light scattering (DLS), MФ-NP(L\&K) showed a hydrodynamic diameter larger than that of the uncoated PLGA cores with a less negative surface zeta potential, consistent with the addition of a membrane bilayer structure (Fig. 1f). Notably, values of the diameter and zeta potential of $M \Phi-N P(L \& K)$ were comparable to those of nanoparticles coated with macrophage membrane alone (denoted ' $М \Phi-N P$ '), indicating negligible impacts from membrane incorporation of MJ-33 and melittin. When visualized with transmission electron microscopy (TEM), $\mathrm{M} \Phi-\mathrm{NP}(\mathrm{L} \& \mathrm{~K})$ showed a core-shell structure that indicated a unilamellar membrane coating around the polymeric core (Fig. $1 \mathrm{~g})^{22,28}$. The membrane coating bestowed MФ-NP(L\&K) with extended colloidal stability in both $1 \times$ phosphate-buffered saline (PBS) and $0.5 \times$ fetal bovine serum (FBS) (Fig. 1h). Whereas free MJ-33 was shown to be toxic to macrophages, MФ-NP(L\&K) with equivalent MJ-33 were nontoxic (Fig. 1i), suggesting a strong association of MJ-33 to the nanoparticles that prevented its participation in cell signaling for toxicity. A series of quality assurance specifications were established to ensure the physicochemical and biological reproducibility of fabricating MФ-NP (L\&K) (Supplementary Table 1).

Next, $M \Phi-N P(L \& K)$ were examined for their anti-PLA2 activity in vitro. They were added to serum samples collected from mice with caerulein-induced acute pancreatitis (CAE-AP) that contained elevated levels of PLA2 (Fig. 2a). MФ-NP(L\&K) showed a clear inhibitory effect against PLA2, with an $\mathrm{IC}_{50}$ value (half-maximal inhibitory concentration) of $72.6 \mu \mathrm{g} / \mathrm{ml}$. The inhibition capacity measured from $\mathrm{M} \Phi-\mathrm{NP}(\mathrm{MJ})$ was lower $\left(\mathrm{IC}_{50}=110.2 \mu \mathrm{g} / \mathrm{ml}\right)$, attributable to the absence of melittin, which helps to potentiate the inhibition. Meanwhile, MФ-NP and MФ-NP(mel) (melittin-incorporated MФ-NP) were unable to inhibit PLA2 in the serum samples. The inhibitory effect of $М \Phi$ $\mathrm{NP}(\mathrm{L} \& \mathrm{~K})$ was also tested on human serum samples from patients with AP. Similarly, MФ-NP(L\&K) effectively inhibited PLA2 activity in samples from all three patients $\left(\mathrm{IC}_{50}=245,255\right.$, and $188 \mu \mathrm{g} / \mathrm{ml}$, Fig. 2b). In contrast, a weaker inhibition was observed with $\mathrm{M} \Phi-\mathrm{NP}(\mathrm{MJ})\left(\mathrm{IC}_{50}=630,673\right.$, and $614 \mu \mathrm{g} / \mathrm{ml}$, respectively), and no inhibition was observed with MФ-NP and MФ-NP(mel). 
a

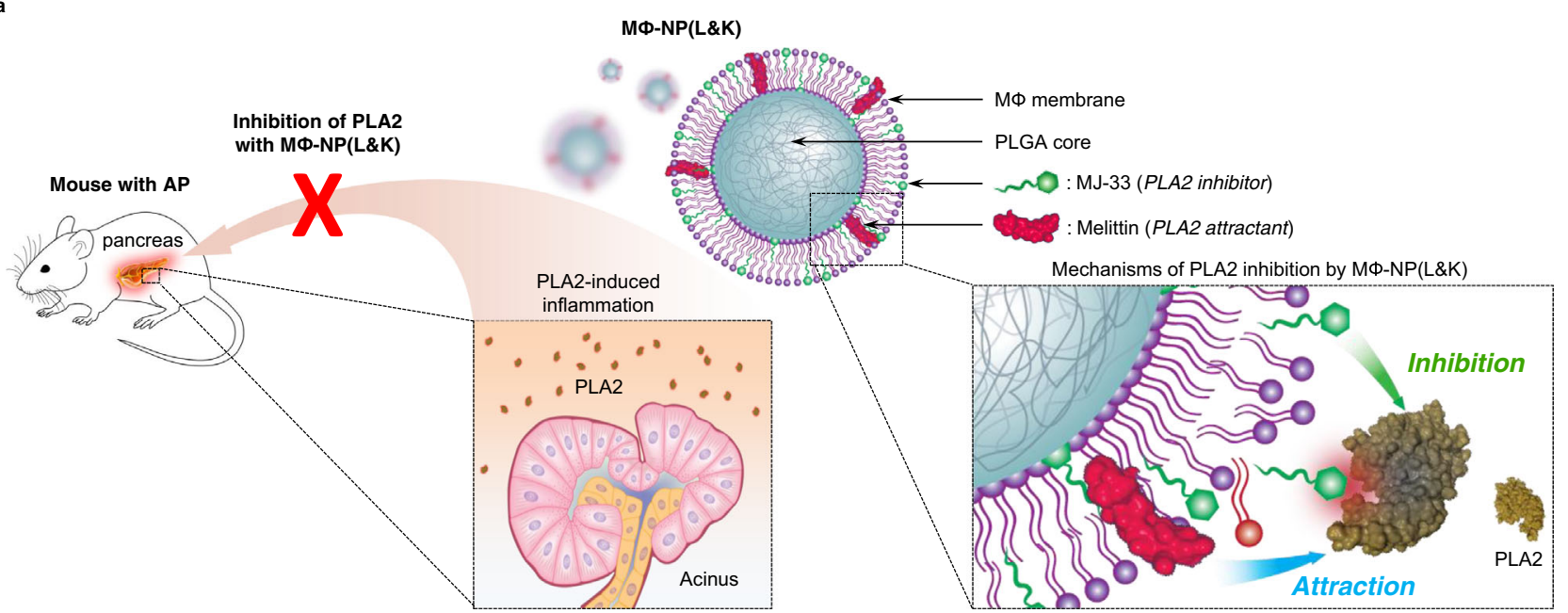

b
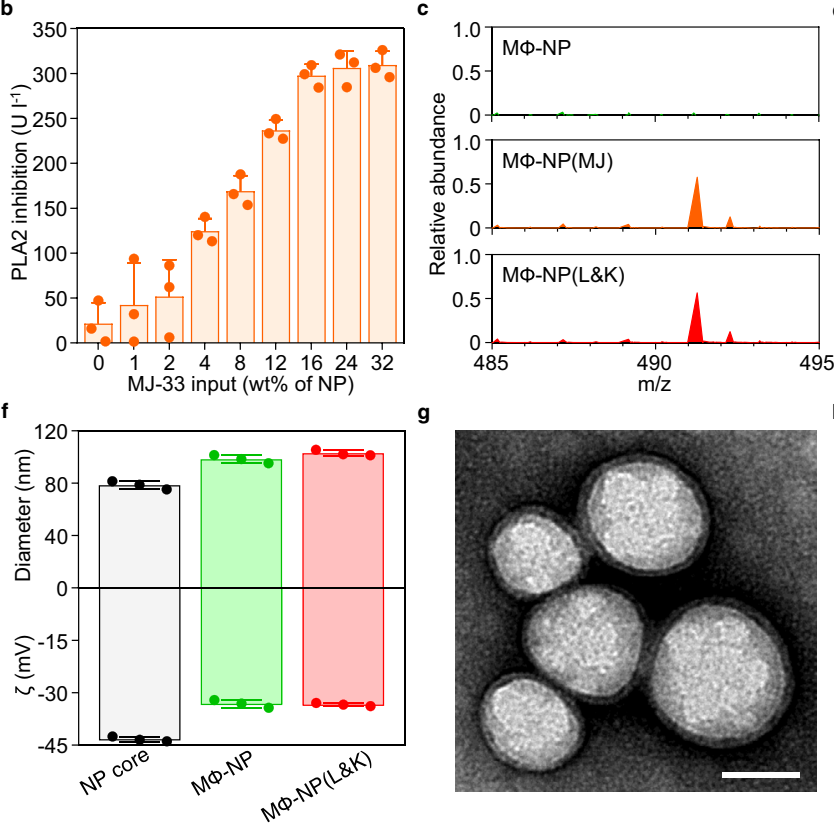
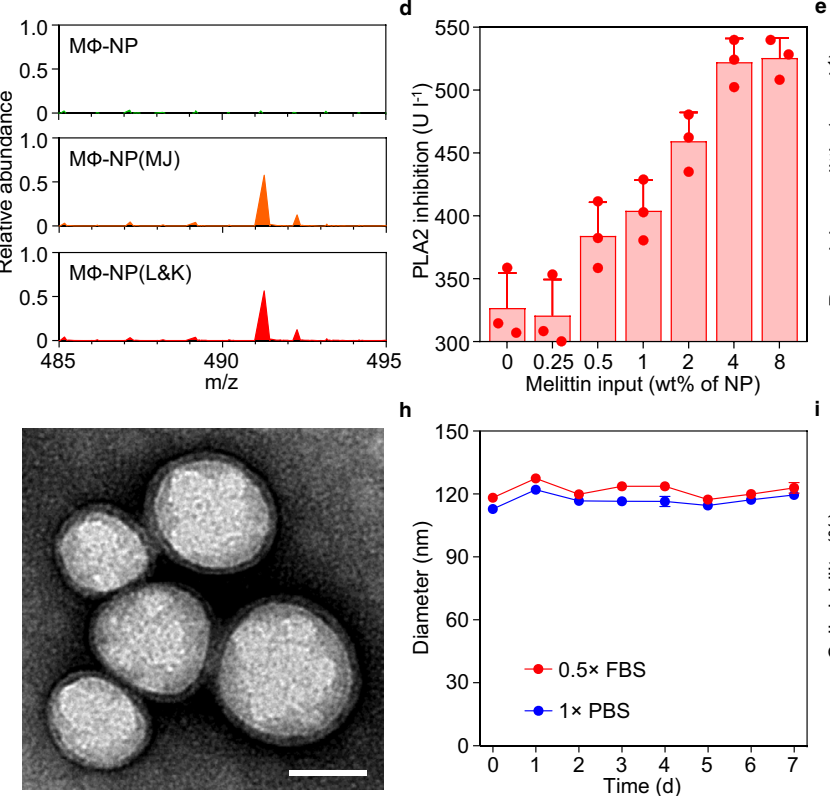

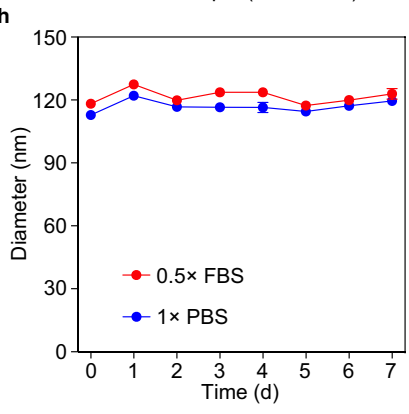

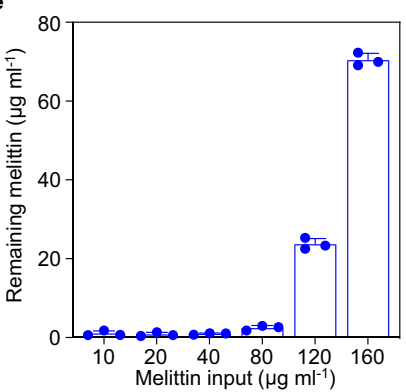

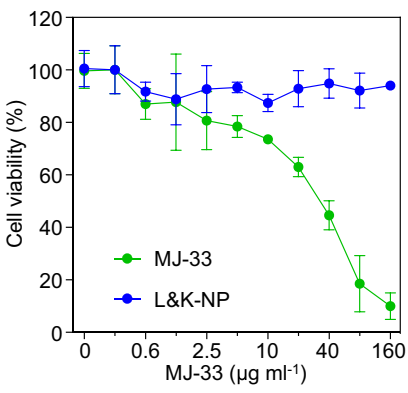

Fig. 1 Fabrication and characterization of $\mathbf{M \Phi - N P ( L \& K ) . ~ a ~ S c h e m a t i c ~ r e p r e s e n t a t i o n ~ o f ~ M \Phi - N P ( L \& K ) ~ d e s i g n e d ~ t o ~ i n h i b i t ~ P L A 2 ~ d u r i n g ~ A P ~ p r o g r e s s i o n . ~}$ b Optimization of MJ-33 input into M $\Phi-N P$ with a PLA2 inhibition assay. c Confirmation of MJ-33 loading into M $\Phi-N P(M J)$ using mass spectrometry (MS).

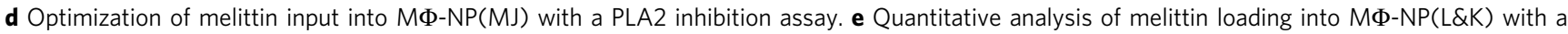
hemolysis assay. $\mathbf{f}$ DLS measurements of $M \Phi-N P(L \& K)$ for hydrodynamic size (diameter, nm) and zeta potential $(\zeta$, mV). $\mathbf{g} A$ representative image of

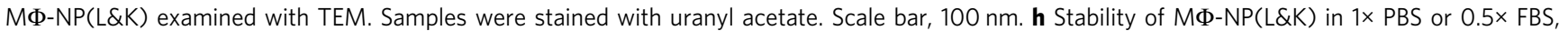
assessed by monitoring nanoparticle size (diameter) over $7 \mathrm{~d}$. i Comparison of the cytotoxicity of free MJ-33 and M $\Phi-N P(L \& K$ ) loaded with equivalent amounts of MJ-33 on mouse J774A.1 macrophages. In all studies, $n=3$ independent experiments using the same batch of corresponding nanoparticles. In (b, d), and (e), data presented as mean + s.d.. In (f, h), and (i), data presented as mean \pm s.d. Source data are provided as a Source Data file for (b-f, h, i).

Overall, these results demonstrated a 'lure and kill' mechanism through the interplay among lipid membrane, melittin, and MJ33 that together suppressed PLA2 activity. Toward systemic applications, the circulation time of MФ-NP(L\&K) was measured with fluorescently labeled nanoparticles after intravenous administration (Fig. 2c). At 24 and $48 \mathrm{~h}, \mathrm{M} \Phi-\mathrm{NP}(\mathrm{L} \& \mathrm{~K})$ showed $17.4 \%$ and $8.0 \%$ retention in the blood, respectively. Based on a twocompartment model, the elimination half-life was calculated as $18.9 \mathrm{~h}$, comparable to the value measured from $\mathrm{M} \Phi-\mathrm{NP}^{27}$. The in vivo tissue distribution of $\mathrm{M} \Phi-\mathrm{NP}(\mathrm{L} \& \mathrm{~K})$ was also evaluated (Fig. 2d). When analyzed per organ, MФ-NP(L\&K) distributed mostly in the blood and the liver. When normalized per gram of tissue, the nanoparticles were largely contained in the liver and spleen, two primary organs of the reticuloendothelial system. Meanwhile, significant fluorescence was also observed in the blood. As the blood fluorescence decreased, a corresponding increase in signal was observed in the liver, indicating the uptake of $M \Phi-N P(L \& K)$ by the reticuloendothelial system over time ${ }^{29}$. To evaluate the safety of MФ-NP(L\&K), PBS or MФ-NP(L\&K) $\left(80 \mathrm{mg} \mathrm{kg}^{-1}\right)$ was intravenously injected into healthy mice daily for 4 days. During the course of the study, the change of body weight in mice receiving $M \Phi-N P(L \& K)$ was comparable to that of the mice receiving PBS (Fig. 2e). Blood cell count and a comprehensive metabolic panel were performed $24 \mathrm{~h}$ after the last nanoparticle injection (Fig. 2f, g, Supplementary Table 2). Compared to mice receiving PBS only, mice receiving $М \Phi-\mathrm{NP}$ (L\&K) showed the absence of toxicity in major organs, including the liver, heart, lungs, kidney, spleen, and pancreas (Fig. 2h). Together, these results indicate a high safety profile for the МФNP(L\&K). 

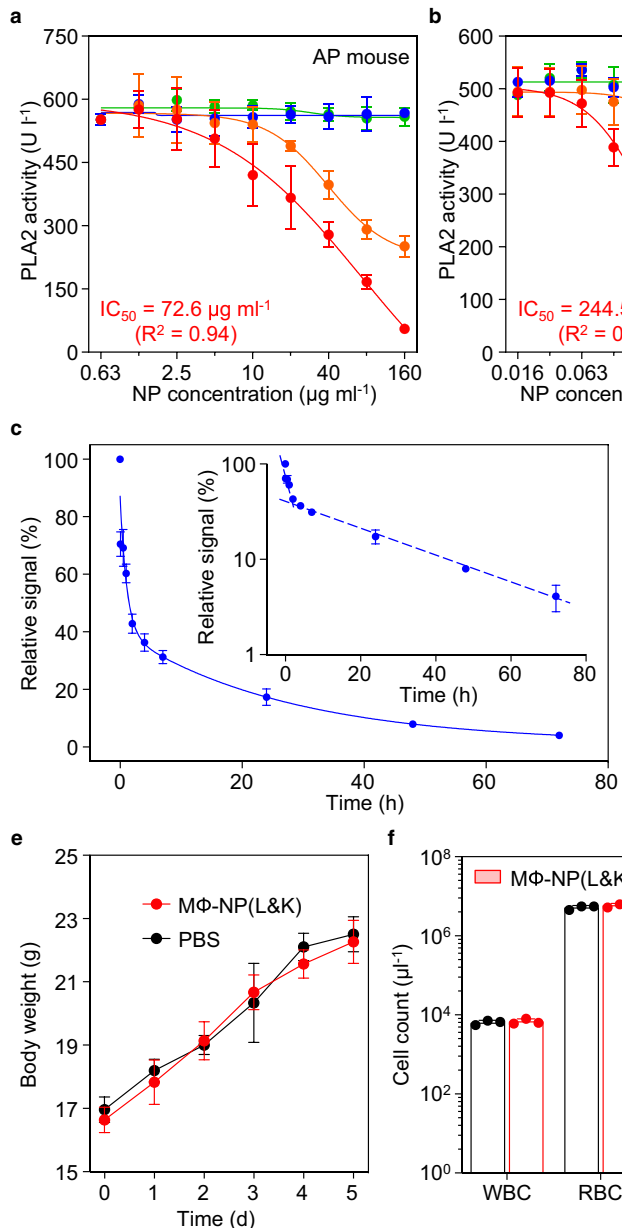

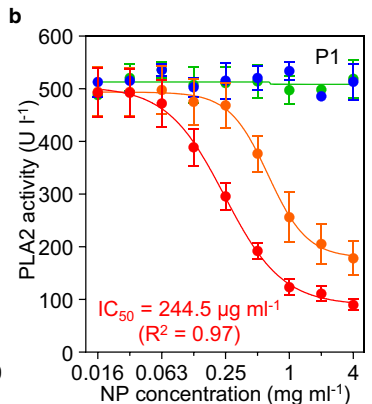

d

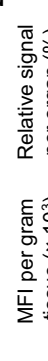

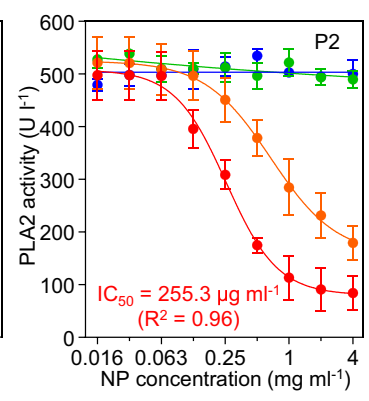
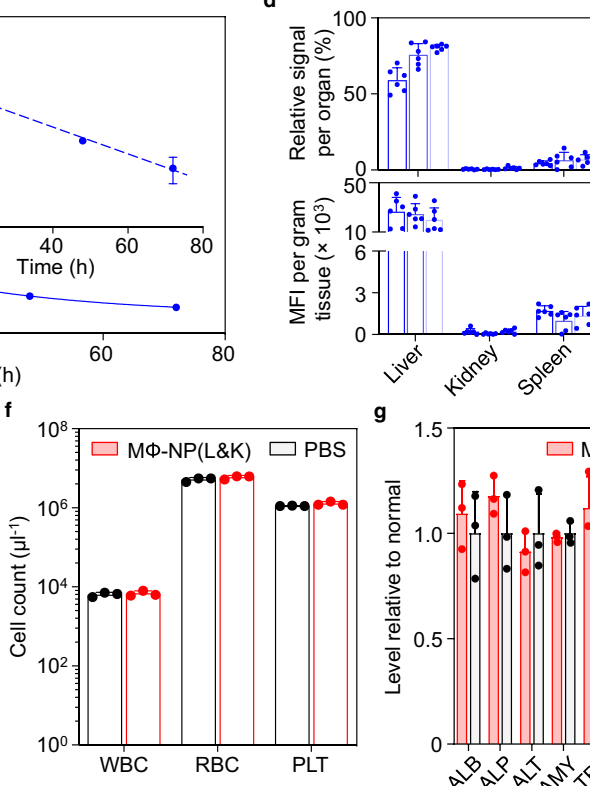

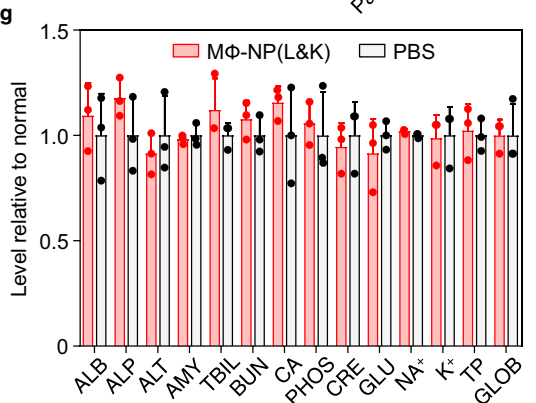

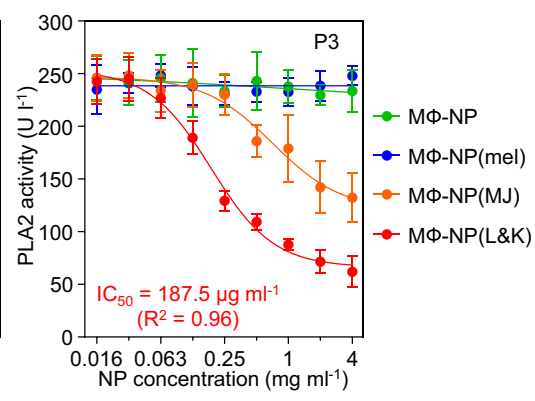

h

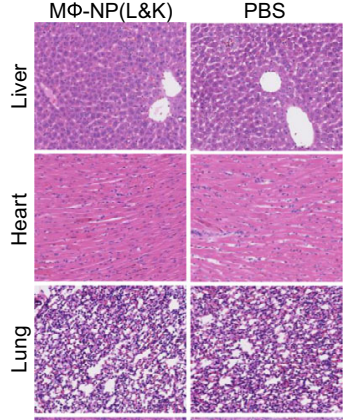

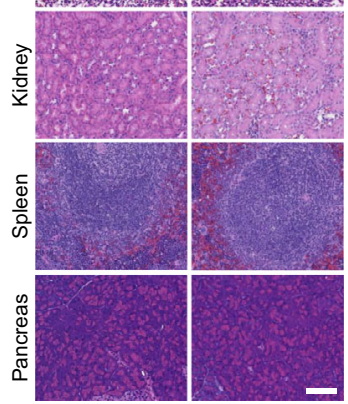

Fig. 2 PLA2 inhibition capacity and in vivo characterizations. Comparison of the inhibition capacity of $M \Phi-N P, M \Phi-N P(m e l), M \Phi-N P(M J)$, and $M \Phi-N P$ $(L \& K)$ against PLA2 in serum from mice with acute pancreatitis (a) and human patients with acute pancreatitis (b). c Pharmacokinetics of M $\Phi-N P(L \& K)$. DiR-loaded nanoparticles were injected intravenously through the tail vein of mice. At various timepoints, blood was withdrawn intraorbitally and measured for fluorescence at $780 \mathrm{~nm}$ to evaluate the systemic circulation lifetime of the nanoparticles (inset, semi-log plot of fluorescence at various timepoints). d Biodistribution of $M \Phi-N P(L \& K)$. Fluorescently labeled nanoparticles were injected intravenously into the mice. At each timepoint (24, 48 , and $72 \mathrm{~h}$ ), the organs from a randomly grouped subset of mice were collected, homogenized, and quantified for fluorescence (top: relative signal per organ, bottom: fluorescence intensity per gram of tissue). e-h Safety of $M \Phi-N P(L \& K)$. Healthy mice received intravenous injections of PBS or M $\Phi-N P(L \& K)$ ( 80 mg/kg) daily on days 1-4. e Body weights of mice taken from day 0 to day 5. f Blood cell counts measured on day 5. WBC white blood cells, RBC red blood cells, PLT platelets. $\mathbf{g}$ Comprehensive blood chemistry panel performed on day 5. ALB albumin, ALP alkaline phosphatase, ALT alanine transaminase, AMY amylase, TBIL total bilirubin, BUN blood urea nitrogen, CA calcium, PHOS phosphorus, CRE creatinine, GLU glucose, NA+ sodium, K+ potassium, TP total protein, GLOB globulin (calculated). h H\&E-stained histological sections from major organs on day 5. Scale bar, $100 \mu \mathrm{m}$. Data presented as mean \pm s.d. In all in vitro studies, $n=3$ independent experiments using the same batch of $M \Phi-N P(L \& K)$. IC $C_{50}$ values were derived from the variable slope model with Graphpad Prism 8. In circulation lifetime and biodistribution studies, $n=6$ using the same batch of M $\Phi-N P(L \& K)$. In systemic toxicity studies, $n=3$ independent experiments using the same batch of $M \Phi-N P(L \& K)$. In $(\mathbf{f}, \mathbf{g})$, the statistical analysis was performed by using the two-tailed paired Student's $t$-test with Microsoft Excel. The difference between PBS and M $\Phi-N P(L \& K)$ groups was not statistically significant $(P=0.38,0.37$, and 0.21 for comparison of counts of WBC, RBC, PLT, respectively). The difference of blood chemistry markers was not significant (Supplementary Table 2). Source data are provided as a Source Data file for $(\mathbf{a}-\mathbf{g})$.

Inhibition of pancreatitis-associated inflammation and acinar cell injury. $M \Phi-\mathrm{NP}(\mathrm{L} \& \mathrm{~K})$ were examined for their ability to inhibit pancreatitis-associated NF- $\kappa \mathrm{B}$ activation in macrophages (Fig. 3a) ${ }^{30}$. When naive macrophages were stained for p65, a subunit of NF- $\kappa \mathrm{B}$, higher fluorescence intensity was observed in the cytoplasm relative to that in the nuclear zone, corresponding to a low nuclear translocation (1.2\%). In contrast, in macrophages exposed to the serum of CAE-AP mice, p65 appeared in both the cytosol and the nuclear zone. In this case, the nuclear translocation increased significantly (58.7\%), indicating NF- $\kappa \mathrm{B}$ activation. Macrophages exposed to the serum mixed with MФ-NP $(\mathrm{L} \& \mathrm{~K})$ showed a reduced $\mathrm{p} 65$ distribution in the nuclear zone in relation to that in the cytosol. The lower nuclear translocation
(17.5\%) implied inhibition of NF- $\kappa B$ activation by the MФ-NP (L\&K). In comparison, macrophages exposed to the serum mixed with control nanoparticles, including $\mathrm{M} \Phi-\mathrm{NP}, \mathrm{M} \Phi-\mathrm{NP}(\mathrm{mel})$, or $\mathrm{M} \Phi-\mathrm{NP}(\mathrm{MJ})$, all exhibited pronounced NF- $\mathrm{\kappa B}$ activation (54.2, 54.6 , and $48.8 \%$ of the nuclear translocation, respectively). Next, $\mathrm{M} \Phi-\mathrm{NP}(\mathrm{L} \& \mathrm{~K})$ were examined for their ability to inhibit of proinflammatory cytokine production in macrophages (Fig. 3b) ${ }^{31}$. Macrophages exposed to the serum of CAE-AP mice produced a higher level of IL- 6 , but the production was inhibited when the serum was also added with $M \Phi-N P(L \& K)$. The inhibition increased as the concentration of $M \Phi-N P(L \& K)$ increased. At all concentrations tested, MФ-NP(L\&K) inhibited IL-6 production more than all control formulations. In addition to IL-6, analysis 

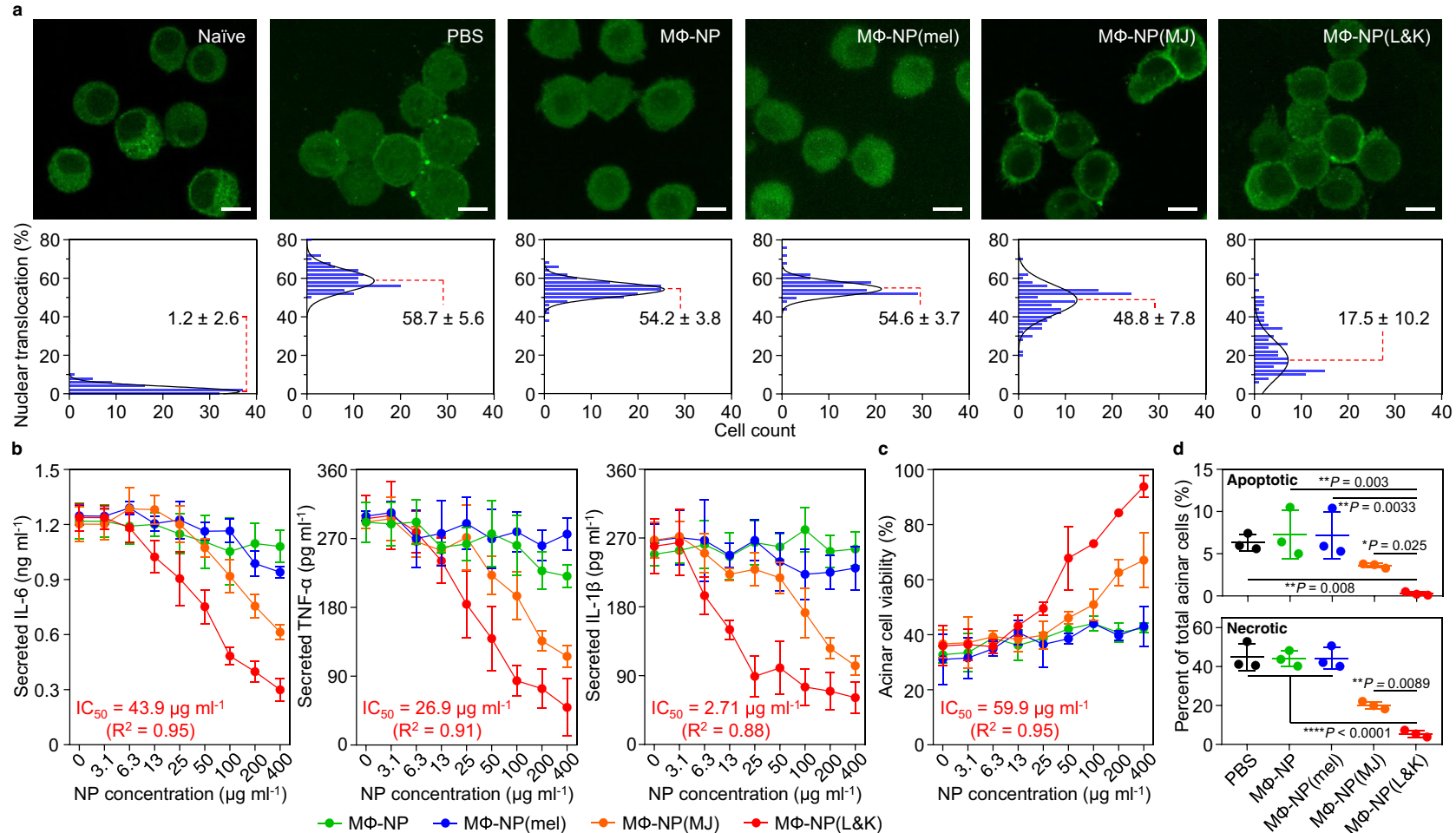

Fig. 3 Suppression of PLA2-induced inflammatory response in vitro. a Effects of $M \Phi-N P(L \& K)$ and control formulations on $N F-\kappa B$ nuclear translocation of PLA2-stimulated macrophages. Representative fluorescence images (top row, scale bar, $10 \mu \mathrm{m}$ ) and quantification of nuclear translocation (bottom row) based on corresponding fluorescence images. $\mathbf{b}$ Effects of M $\Phi-N P(L \& K)$ and control formulations on IL-6, TNF- $\alpha$, and IL-1 $\beta$ production from PLA2stimulated macrophages. c Effects of $M \Phi-N P(L \& K)$ and control formulations on cell viability of PLA2-stimulated pancreatic acinar cells. d Effects of M $\Phi$ $\mathrm{NP}(L \& K)$ and control formulations on apoptosis and necrosis analyzed by flow cytometry using annexin $\mathrm{V} / \mathrm{PI}$ double staining. Results were analyzed by using one-way ANOVA with Dunnett's post hoc analysis in Graphpad Prism. Data presented as mean \pm s.d. In all datasets, $n=4$ independent experiments using the same batch of $M \Phi-N P(L \& K) . I_{50}$ and $E_{50}$ values were derived from the variable slope model using Graphpad Prism 8 . Source data are provided as a Source Data file for (a-d)

on additional pro-inflammatory cytokines, including TNF- $\alpha$ and IL-1 $\beta$, also showed similar inhibition effects.

Acinar cell death is a hallmark of $\mathrm{AP}^{32}$, and $\mathrm{M} \Phi-\mathrm{NP}(\mathrm{L} \& \mathrm{~K})$ were thus examined for their ability to protect PACs. Exposure to the serum of CAE-AP mice significantly reduced the viability of PACs (Fig. 3c). However, viability increased when MФ-NP(L\&K) were added to the PACs, indicating a protective effect against cell death. The cell viability increased as the nanoparticle concentration increased, corresponding to an $\mathrm{EC}_{50}$ (half-maximal effective concentration) value of $59.9 \mu \mathrm{g} / \mathrm{ml}$. A dose-dependent increase of PAC viability was also observed when $\mathrm{M} \Phi-\mathrm{NP}(\mathrm{MJ})$ were added, but a lower $\mathrm{EC}_{50}$ value was obtained $(363 \mu \mathrm{g} / \mathrm{ml})$. PACs added with $\mathrm{M} \Phi-\mathrm{NP}$ and $\mathrm{M} \Phi-\mathrm{NP}(\mathrm{mel})$ showed viability no higher than $50 \%$, suggesting that they were ineffective in protecting PACs from the serum. The protection was further analyzed for APC necrosis and apoptosis (Fig. 3d and Supplementary Fig. 4). Exposure to the serum of CAE-AP mice resulted in significant portions of necrotic and apoptotic cells. When MФ-NP(L\&K) were added to the cells, the percentages of both cell populations were reduced, confirming the nanoparticles were able to protect against cell death. Similarly, MФ-NP(MJ) showed partial protection of the APCs, whereas MФ-NP and MФ-NP(mel) showed negligible protection.

Protection of mice with mild acute pancreatitis. MФ-NP(L\&K) were further evaluated for their protective effects in a mouse model of mild acute pancreatitis (CAE-AP) induced by intraperitoneal injections of caerulein ${ }^{33}$. Following AP induction, MФ$\mathrm{NP}(\mathrm{L} \& \mathrm{~K})$ or control formulations, including MФ-NP, MФ-NP (mel), MФ-NP(MJ), and PBS, were injected intravenously through the mouse tail vein for efficacy evaluation (Fig. 4a). First, the treatment efficacy was evaluated at a systemic level by examining serum levels of PLA2 and pro-inflammatory cytokines, including IL- 6 , TNF- $\alpha$, and IL- $1 \beta$, for $24 \mathrm{~h}$ during the disease progression (Fig. $4 \mathrm{~b}-\mathrm{e}$ ). In the study, the injection of caerulein led to a rapid increase of serum PLA2 level, which reached a maximum in $2 \mathrm{~h}$ and then gradually decreased. Throughout the study, the PLA2 level in mice injected with MФ-NP(L\&K) $(40 \mathrm{mg} / \mathrm{kg}$, Supplementary Fig. 5) remained significantly lower compared to PLA2 levels in all other groups treated with control formulations, indicating an inhibitory effect against AP development. Meanwhile, the injection of caerulein also boosted serum cytokine levels, which reached maximum in $4 \mathrm{~h}$ and then started to decrease. The levels of these cytokines in mice injected with МФ$\mathrm{NP}(\mathrm{L} \& \mathrm{~K})$ remained significantly lower compared to those in mice injected with control formulations, further confirming the inhibition of AP by MФ-NP(L\&K). Notably, MФ-NP(L\&K) showed a significantly higher inhibition than $M \Phi-N P(M J)$, suggesting the role of melittin in further potentiating anti-PLA2 effects.

Next, the efficacy of $M \Phi-N P(L \& K)$ was evaluated at a tissue level by examining the pathological changes of the pancreas during the treatment. In the study, mice were sacrificed $24 \mathrm{~h}$ after the initial AP induction. The pancreas was harvested for histopathological analysis. As shown in Fig. 4f, H\&E-stained pancreatic sections from healthy naive mice showed tight interlobular and intralobular spaces, with the absence of acinar necrosis or immune infiltration. However, tissue sections from CAE-AP mice injected with PBS exhibited diffuse widening of 

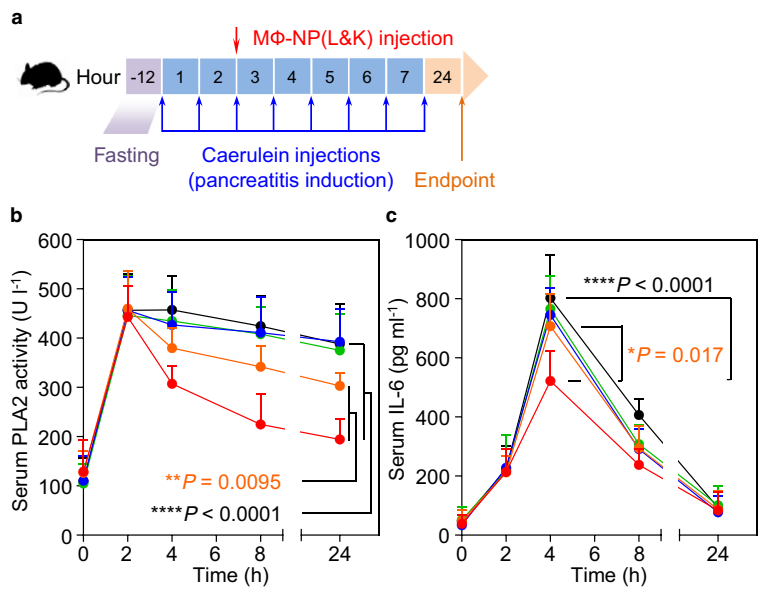

d

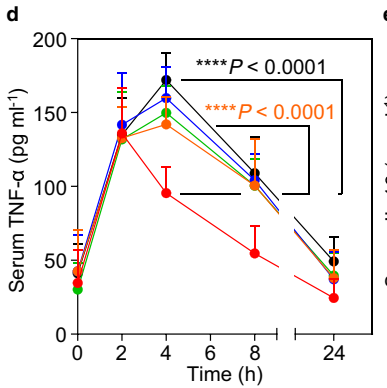

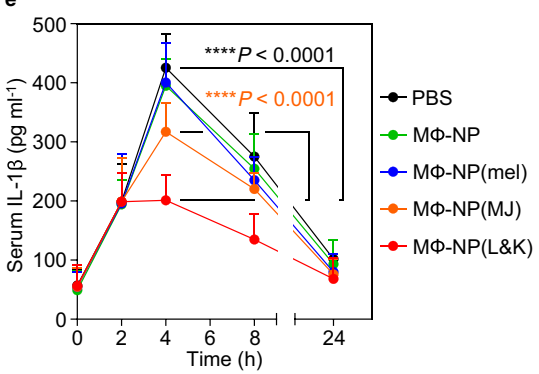

faïve
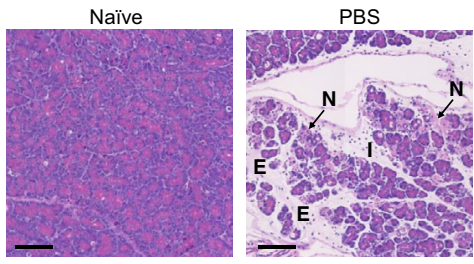

MФ-NP
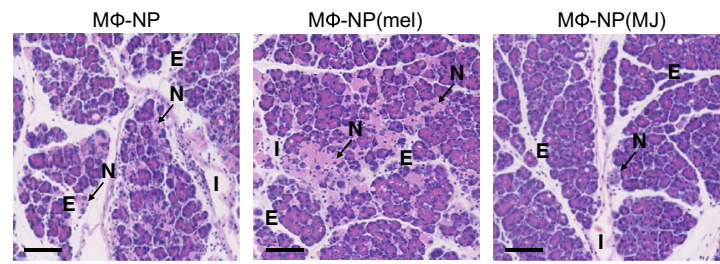

MФ-NP(L\&K)

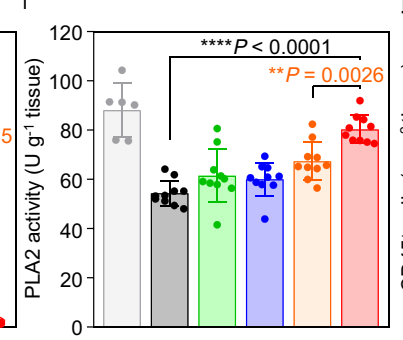

j
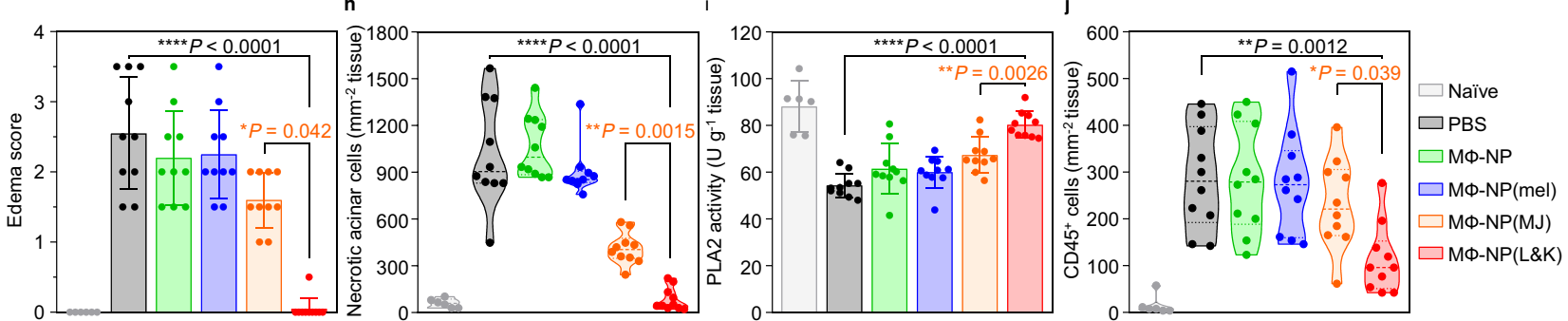

Fig. 4 Therapeutic efficacy in a mouse model of mild acute pancreatitis. a The study protocol of pancreatitis induction and treatment with $M \Phi-N P(L \& K)$. b PLA2 activity profile in serum of CAE-AP mice treated with different nanoparticle formulations. Concentration profiles of key inflammatory cytokines, including IL-6 (c), TNF- $\alpha(\mathbf{d})$, and IL-1 $\beta(\mathbf{e})$, in the serum of CAE-AP mice treated with different nanoparticle formulations. $\mathbf{f}$ Representative images of H\&E staining on pancreas sections from CAE-AP mice collected $24 \mathrm{~h}$ after receiving the treatments. Scale bars, $100 \mu \mathrm{m}$. $\mathrm{N}$ acinar necrosis, E edema, I cell infiltration. $\mathbf{g}$ Edema score of H\&E-stained pancreas sections from CAE-AP mice after receiving different nanoparticle treatments. $\mathbf{h}$ Quantification of necrotic cells in the H\&E-stained pancreas sections from CAE-AP mice receiving different nanoparticle treatments. i PLA2 activity in the pancreatic tissue of CAE-AP mice treated with different nanoparticle formulations. $\mathbf{j}$ Quantification of CD45+ cells in the anti-CD45-stained pancreas sections from CAE-AP mice receiving different nanoparticle treatments. For serum PLA2 and cytokine profiles, statistical analysis was performed using repeated-measure oneway ANOVA with Dunnett's post hoc analysis. Statistical difference in edema scores was analyzed by Kruskal-Wallis non-parametric test with Dunnett's post hoc analysis. Necrotic cell counts, tissue PLA2 activity, and CD45+ cell counts were analyzed by using one-way ANOVA with Dunnett's post hoc analysis. Data presented as mean \pm s.d. ${ }^{\star} P \leq 0.05,{ }^{\star \star} P \leq 0.01,{ }^{\star \star \star} P \leq 0.001,{ }^{\star \star \star \star} P \leq 0.0001$. In all datasets, $n=10$ mice treated with the same batch of $M \Phi-$ $\mathrm{NP}(L \& K)$. Source data are provided as a Source Data file for $(\mathbf{b}-\mathbf{e}, \mathbf{g}-\mathbf{j})$.

interlobular and intralobular spaces (edema), marked acinar necrosis, and evident cell infiltration into the interlobular spaces. Similar features were also observable in sections from CAE-AP mice injected with $\mathrm{M} \Phi-\mathrm{NP}, \mathrm{M} \Phi-\mathrm{NP}(\mathrm{mel})$, or $\mathrm{M} \Phi-\mathrm{NP}(\mathrm{MJ})$, indicating a lack of efficacy from these formulations. In contrast, the tissue of CAE-AP mice injected with MФ-NP(L\&K) appeared similar to that of healthy naive mice without obvious acinar necrosis or immune infiltration, demonstrating clear protection of the pancreas during AP. Comprehensive histopathological analysis was performed on sections from all animals in the study (Supplementary Figs. 6-8) ${ }^{34}$. Based on such analysis, the degree of pancreatic edema was evaluated by scoring the extent of interlobular and intralobular space widening in the pancreatic sections (Fig. 4g and Supplementary Figs. 7-12). While mice injected with PBS received an edema score of $2.6 \pm 0.8$, those injected with $M \Phi-N P(L \& K)$ had a significantly reduced score of $0.1 \pm 0.1$, comparable to that of the healthy naive mice. Scores from mice injected with control nanoparticles remained significantly higher, indicating a lack of protection on the pancreas. Furthermore, counts of necrotic acinar cells were elevated in CAE-AP mice injected with PBS, but remained at the basal levels in those injected with MФ-NP(L\&K) (Fig. 4h). Notably, mice injected with $\mathrm{M} \Phi-\mathrm{NP}(\mathrm{MJ})$ showed a partial reduction of necrotic acinar cell count, likely due to the presence of the inhibitor without melittin. The pancreatic tissues were also examined for PLA2 activity (Fig. 4i). At $24 \mathrm{~h}$ after the initial AP induction, mice injected with PBS showed a reduced level of PLA2 in the pancreas when compared with the naive mice, indicating the loss of PLA2 due to acinar injury ${ }^{35}$. In contrast, pancreatic PLA2 levels were comparable between healthy mice and mice injected with $M \Phi-N P(L \& K)$, indicating the protection of normal acinar functions. Furthermore, the immune infiltration into the pancreatic parenchyma was examined by staining the pancreatic sections for CD45, a pan-leukocyte marker (Supplementary Fig. 13) ${ }^{36}$. As shown in Fig. 4j, a higher level of infiltrating leukocytes was found in CAE-AP mice compared to 
healthy naive mice. The level was also elevated in mice treated with $\mathrm{M} \Phi-\mathrm{NP}, \mathrm{M} \Phi-\mathrm{NP}(\mathrm{mel})$, or $\mathrm{M} \Phi-\mathrm{NP}(\mathrm{MJ})$. Compared to these groups, counts of $\mathrm{CD} 45^{+}$cells were significantly lower in mice treated with $\mathrm{M} \Phi-\mathrm{NP}(\mathrm{L} \& \mathrm{~K})$, indicating a clear reduction of disease severity.

Protection of mice with severe acute pancreatitis. The protective effects of $M \Phi-N P(L \& K)$ were further evaluated in a mouse model of severe AP (CDE-AP) induced by feeding mice with a choline-deficient diet supplemented with DL-ethionine. The diet intake period was positively correlated with the severity of AP (Supplementary Fig. 14) ${ }^{37}$. In the study, female CD-1 mice were placed on a CDE-diet for 3 days and each day MФ-NP(L\&K) were injected along with other control formulations for efficacy evaluation (Fig. 5a). A dosage of $80 \mathrm{mg} / \mathrm{kg}$ per injection was selected (Supplementary Fig. 15). As shown in Fig. 5b, all mice injected with PBS, МФ-NP, or MФ-NP(mel) died by day 4, indicating a lack of therapeutic efficacy from the control nanoparticles. Meanwhile, the survival rate of those injected with МФ$\mathrm{NP}(\mathrm{MJ})$ was only $20 \%$, suggesting ineffective protection if only MJ-33 was incorporated into the nanoparticles. In contrast, the survival rate of mice injected with $M \Phi-N P(L \& K)$ increased significantly to $60 \%$, demonstrating a clear benefit against AP development. As another evaluation of the efficacy at a systemic level, we monitored serum levels of PLA2, together with proinflammatory cytokines, including IL- 6 , TNF- $\alpha$, and IL- $1 \beta$, during days $0-3$ of the study, a period prior to the occurrence of any death (Fig. $5 c-f$ ). Intake of CDE-diet drastically elevated serum PLA2 and cytokine levels in mice injected with PBS, which plateaued after day 2. On day 2 and day 3 , serum PLA2 and cytokine levels in mice administered with $M \Phi-N P(L \& K)$ remained significantly lower than those in all control groups. The results demonstrated the effective suppression of serum PLA2 and cytokines in CDE-AP, indicating a protective effect of MФ-NP (L\&K).

MФ-NP(L\&K) against severe AP was further evaluated by examining the histopathological changes in the pancreatic tissue during disease progression. In the study, mice were euthanized on day 3 of AP induction and the pancreatic tissues were collected for analyses. The pancreatic sections from naive mice displayed characteristics of a normal healthy pancreas including tight interlobular space and absence of acinar necrosis or immune infiltration (Fig. 5g). In contrast, the sections from CDE-AP mice injected with PBS showed marked parenchymal edema, pronounced acinar necrosis, and obvious signs of hemorrhage, which all are characteristic features of severe $\mathrm{AP}^{37}$. These features were also clearly observable in mice injected with $\mathrm{M} \Phi-\mathrm{NP}, \mathrm{M} \Phi-\mathrm{NP}$ (mel), or $\mathrm{M} \Phi-\mathrm{NP}(\mathrm{MJ})$, indicating a lack of therapeutic efficacy from these formulations. Comprehensive histopathological analyses revealed a significantly reduced edema score in mice injected with $\mathrm{M} \Phi-\mathrm{NP}(\mathrm{L} \& \mathrm{~K})$, compared to mice receiving PBS or control formulations (Fig. $5 \mathrm{~h}$ and Supplementary Figs. 16-21). In addition, counts of necrotic acinar cells were effectively reduced to basal levels in mice injected with $M \Phi-N P(L \& K)$ (Fig. 5i), further confirming the protective effect of MФ-NP(L\&K) against severe AP. The hemorrhagic area in the pancreatic tissue was also measured and found to be reduced in mice treated with MФ-NP (L\&K) but not in those treated with PBS or control formulations (Fig. 5j). Pancreatic sections were also stained for CD45 for analyses of leukocyte infiltration (Fig. 5k and Supplementary Fig. 22). When compared to healthy naive mice, leukocyte infiltration in those injected with control formulations was significantly elevated but remained significantly lower for $\mathrm{M} \Phi$ $\mathrm{NP}(\mathrm{L} \& \mathrm{~K})$-treated mice. These results again confirmed the ability of MФ-NP(L\&K) in protecting animals against severe AP.
In summary, we exploited the susceptibility of macrophages to pancreatitis-associated PLA2 and designed a biomimetic nanoparticle with a "lure and kill" mechanism for safe and effective inhibition of PLA2. In this design, nanoparticles were made by wrapping with natural macrophage membranes doped with melittin and MJ-33 as PLA2 attractant and inhibitor, respectively. The modified macrophage membrane can eliminate the toxicity of free melittin and MJ-33 molecules while synergistically luring and killing PLA2. When tested in pancreatitis models, the resulting M $\Phi-\mathrm{NP}(\mathrm{L} \& \mathrm{~K})$ were shown to effectively inhibit PLA2 activity and PLA2-induced pancreatic injury. Their administration into mice with AP showed protective effects against APinduced inflammation, tissue damage, and lethality.

The prominent anti-PLA2 activity of MФ-NP(L\&K) makes these biomimetic nanoparticles a promising drug candidate for the treatment of a wide range of PLA2-mediated diseases. Notably, in diseases such as cardiovascular disease, cancer, and autoimmune disorders, systemic PLA2 activity is positively correlated with disease severity and PLA2 inhibition is a desirable strategy ${ }^{38-40}$. In atherosclerosis, PLA2 is known to be responsible for remodeling low-density lipoprotein particles, promoting the aggregation of modified lipoproteins and the generation of foam cells ${ }^{41}$. PLA2 modulates cancer cell proliferation through the arachidonic acid metabolic pathway ${ }^{39}$. In autoimmune disorders such as rheumatoid arthritis, cytosolic PLA2 produces precursors for the synthesis of leukotriene and prostaglandin, which are known to contribute to disease progression ${ }^{42}$. Meanwhile, PLA2 isoforms show unique origins, substrate selectivity, and tissue distribution $^{12}$. To address such complexity, nanoparticle formulations similar to $\mathrm{M} \Phi-\mathrm{NP}(\mathrm{L} \& \mathrm{~K})$ can be made by coating with membranes from other cells sensitive to specific isoforms ${ }^{43-45}$. In addition, the cell membrane could be further modified with other unique compounds that either attract or inhibit PLA2 ${ }^{46,47}$. In the study, we derived the membrane from macrophage cell lines. The possible immune mismatch between the source cells and the recipient animals might limit nanoparticle circulation lifetime. In this regard, source cells could be genetically modified prior to membrane collection to reduce such mismatch ${ }^{48}$. These features ensure $\mathrm{M} \Phi-\mathrm{NP}(\mathrm{L} \& \mathrm{~K})$ design to be finely tailored to precisely target a specific PLA2 in the target disease. AP is a complex and evolving condition and generates multiple damaging factors yet to be understood ${ }^{49-51}$. While multiple animal models of AP have been developed, an effective treatment translatable to humans remains unavailable. Therefore, caution must be taken when envisioning the future development of AP treatment. With these challenges in place, we expect $M \Phi-N P(L \& K)$ to be a useful tool toward developing therapies for $\mathrm{AP}$ and other related medical conditions.

\section{Methods}

Mice. Mice were housed in an animal facility at the University of California San Diego (UCSD) under federal, state, local, and National Institutes of Health (NIH) guidelines. Four-week-old or six-week-old CD-1 female mice were purchased from Envigo. Mice were maintained under standard housing with $12 \mathrm{~h}$ light/ $12 \mathrm{~h}$ dark cycle, ambient temperature, and normal humidity. All animal experiments were performed in accordance with $\mathrm{NIH}$ guidelines and approved by the Institutional Animal Care and Use Committee (IACUC) of UCSD.

Macrophage culture. Mouse J774A.1 cell line (American Type Culture Collection, ATCC) was maintained in Dulbecco's Modified Eagle Medium (DMEM, Invitrogen) supplemented with $10 \%$ FBS (Hyclone) and 1\% penicillin-streptomycin (Invitrogen). Human THP-1 cell line (ATCC) was maintained in RPMI 1640 (Gibco) supplemented with $10 \%$ FBS and 1\% penicillin-streptomycin. Cell cultures were maintained at $37^{\circ} \mathrm{C}$ in a humidified incubator with $5 \% \mathrm{CO}_{2}$ and regularly tested for mycoplasma contamination.

Macrophage membrane derivation. The plasma membrane of macrophages was harvested by following a published protocol ${ }^{27}$. Briefly, J774A.1 cells were grown in 


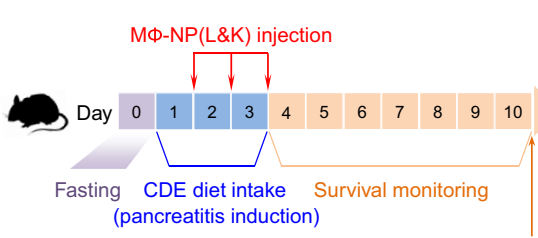

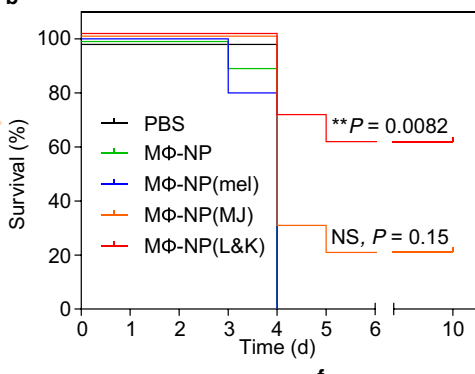

f

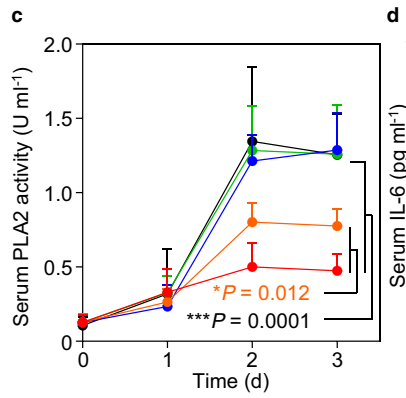

d
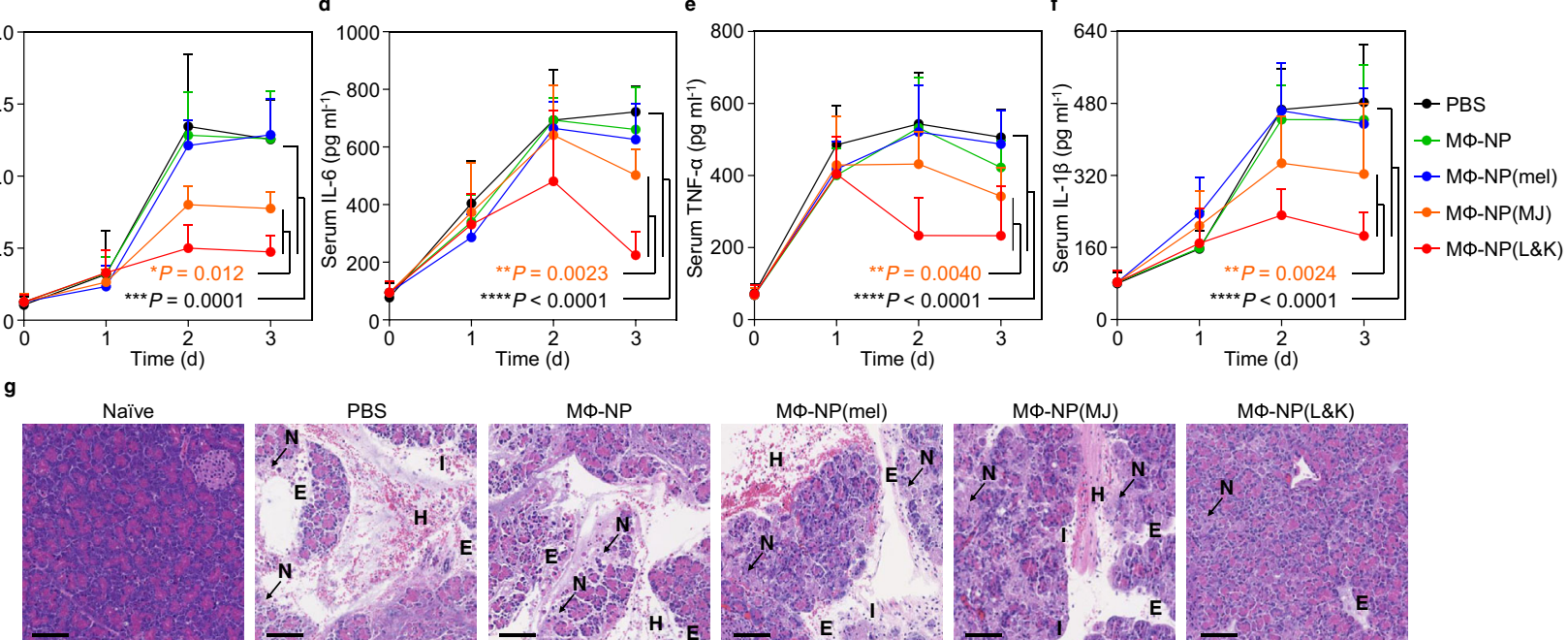

PBS

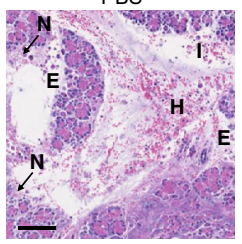

МФ-NP
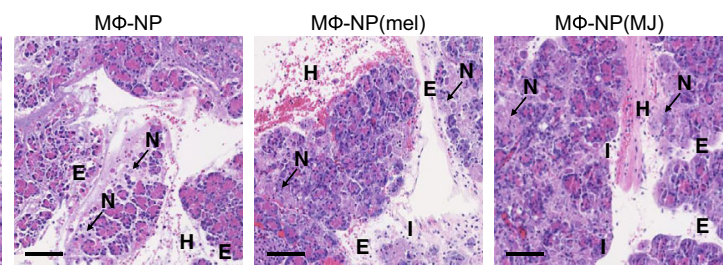

$M \Phi-N P(L \& K)$

h
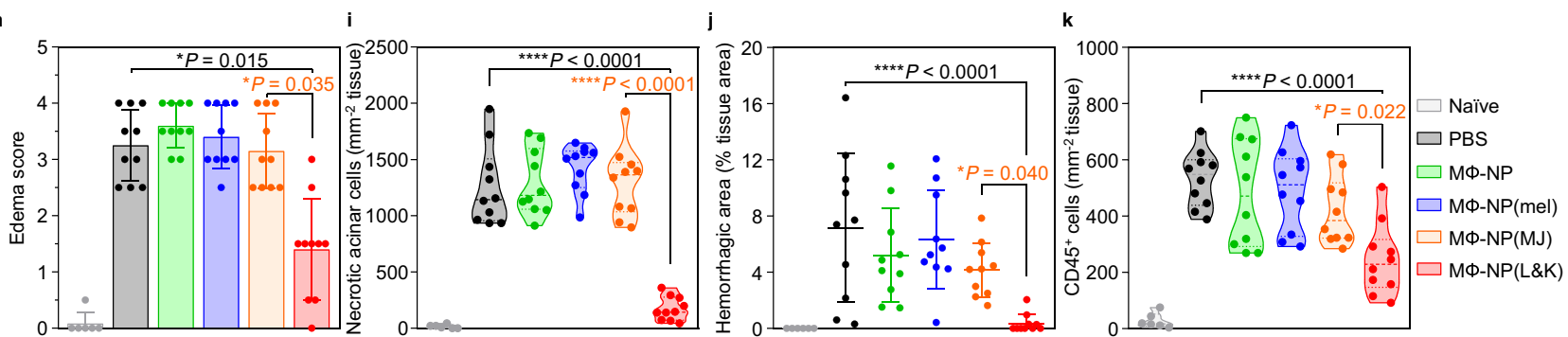

Fig. 5 Therapeutic efficacy in a mouse model of severe acute pancreatitis. a The study protocol of lethal pancreatitis induction and treatment with $M \Phi-$ NP(L\&K). b Survival rates of mice over 10 days after initial diet intake. NS not significant. c PLA2 activity profiles in serum of CDE-AP mice treated with different formulations. Concentration profiles of key inflammatory cytokines, including IL-6 (d), TNF- $\alpha(\mathbf{e})$, and IL-1 $\beta$ (f), of CDE-AP mice treated with different formulations. $\mathbf{g}$ Representative images of H\&E staining on pancreas sections from CDE-AP mice collected on day 3 after initial diet intake. Scale bars, $100 \mu \mathrm{m}$. $\mathrm{N}$ acinar necrosis, E edema, I cell infiltration, $\mathrm{H}$ hemorrhage. $\mathbf{h}$ Edema score of H\&E-stained pancreas sections from CDE-AP mice after receiving different nanoparticle treatments. i Quantification of necrotic cells in the H\&E-stained pancreas sections from CDE-AP mice receiving different nanoparticle treatments. $\mathbf{j}$ Quantification of hemorrhagic area in the H\&E-stained pancreas sections from of CDE-AP mice receiving different nanoparticle treatments. $\mathbf{k}$ Quantification of $C D 45^{+}$cells in the anti-CD45-stained pancreas sections from CDE-AP mice treated with different formulations. For survival study, statistical analysis was performed on groups treated with $M \Phi-M J-N P s$ or $M \Phi-N P(L \& K)$ in comparison with PBS-treated group using a two-tailed log-rank (Mantel-Cox) test. For serum PLA2 and cytokine profiles, statistical analysis was performed using repeated-measure one-way ANOVA with Dunnett's post hoc analysis. Statistical difference in edema scores was analyzed by Kruskal-Wallis non-parametric test with Dunnett's post hoc analysis. Necrotic cell counts, quantification of hemorrhagic area, and CD45+ cell counts were analyzed by using one-way ANOVA with Dunnett's post hoc analysis. Data presented as mean \pm s.d. ${ }^{\star} P \leq 0.05,{ }^{\star \star} P \leq 0.01,{ }^{\star \star \star} P \leq 0.001,{ }^{\star \star \star \star} P \leq 0.0001$. In the study, $n=10$ mice in CDE-AP model. All mice were treated with the same batch of $M \Phi-N P(L \& K)$. Source data are provided as a Source Data file for $(\mathbf{b}-\mathbf{f}, \mathbf{h}-\mathbf{k})$.

T175 culture flasks to full confluency and detached with $3 \mathrm{mM}$ ethylenediaminetetraacetic acid (EDTA, MilliporeSigma) in PBS. The cells were washed with $1 \times$ PBS three times (centrifugation at $800 \times g$ ) and suspended in a hypotonic lysing buffer containing $30 \mathrm{mM}$ Tris- $\mathrm{HCl}(\mathrm{pH}=7.5), 225 \mathrm{mM}$ D-mannitol, $75 \mathrm{mM}$ sucrose, $0.2 \mathrm{mM}$ ethylene glycol-bis( $\beta$-aminoethyl ether)-( $N, N, N^{\prime}, N^{\prime}$-tetraacetic acid) (EGTA), and protease and phosphatase inhibitor cocktails (all from MilliporeSigma). Cells were then disrupted using a Dounce homogenizer with a tightfitting pestle (20 passes). The homogenized solution was centrifuged at $20,000 \times g$ for $25 \mathrm{~min}$ at $4{ }^{\circ} \mathrm{C}$. The pellet was discarded, and the supernatant was centrifuged again at $100,000 \times g$ for $35 \mathrm{~min}$ at $4{ }^{\circ} \mathrm{C}$. Following the centrifugation, membrane was collected as the pellet and washed twice with $0.2 \mathrm{mM}$ EDTA in water. Membrane content was quantified by using a BCA protein assay kit (Thermo Fisher Scientific) in reference to a bovine serum albumin (BSA) standard. Approximately
$1 \times 10^{8}$ macrophages were able to yield $1 \mathrm{mg}$ of membrane material (protein weight). The membrane was suspended with $0.2 \mathrm{mM}$ EDTA to a protein concentration of $10 \mathrm{mg} / \mathrm{ml}$ and stored at $-80^{\circ} \mathrm{C}$ for subsequent studies. To collect membrane from THP-1 cells, the cells were grown in T175 suspension flasks (Olympus Plastics) to a density of $1 \times 10^{6}$ cells $/ \mathrm{ml}$ and washed three times in PBS (centrifugation at $800 \times g$ ). The plasma membrane was then harvested following the same procedure.

Fabrication of $\mathbf{M} \Phi-\mathbf{N P}$. To synthesize nanoparticle cores, $0.4 \mathrm{ml}$ poly(DL-lactic$c o$-glycolic acid) (50:50 PLGA, 0.67 dl/g, Lactel Absorbable Polymers) in acetone $(20 \mathrm{mg} / \mathrm{ml})$ was added dropwise into $1 \mathrm{ml}$ water. The solution was placed below a vacuum aspirator until the acetone evaporated completely. To trace the nanoparticles, PLGA cores were prepared by co-dissolving PLGA with $0.1 \mathrm{wt} \% 1,1^{\prime}$ - 
dioctadecyl-3,3,3',3'-tetramethylindotricarbocyanine iodide ( $\mathrm{DiR}$, excitation $=750$ $\mathrm{nm} / \mathrm{emission}=780 \mathrm{~nm}$, ThermoFisher Scientific). For coating, the macrophage membrane was mixed with PLGA cores at a polymer-to-membrane protein weight ratio of 2:1. The mixture was then sonicated in a bath sonicator (Fisher Scientific FS30D) for 2 min, resulting in M $\Phi-\mathrm{NP}$.

\section{Fabrication of $\mathbf{M J}$-incorporated macrophage membrane-coated nanoparticles.} To incorporate MJ-33, macrophage membrane $(4 \mathrm{mg} / \mathrm{ml}$ in water) was mixed with MJ-33 (0.04-1.28 mg/ml, corresponding to $1-32 \%$ membrane protein weight, dissolved in $100 \%$ ethanol, Cayman Chemicals) and sonicated with the bath sonicator for $30 \mathrm{~s}$ and incubated at $37^{\circ} \mathrm{C}$ for $15 \mathrm{~min}$. The same sonication-incubation cycle was repeated once. The suspension was centrifuged at $20,000 \times g$ for $10 \mathrm{~min}$ and the MJ-33-loaded macrophage membrane was resuspended in water. To form nanoparticles, the MJ-33-loaded macrophage membrane was mixed with PLGA cores at a polymer-to-membrane protein weight ratio of 2:1. The mixture was then sonicated in the bath sonicator for $2 \mathrm{~min}$ for coating, resulting in MФ-NP(MJ). MФ-NP(MJ) were then washed twice with centrifugation. MJ-33 input into the macrophage membrane was optimized by measuring the inhibitory capacity of the resulting $M \Phi$ $\mathrm{NP}(\mathrm{MJ})$ against native bovine PLA2 (Creative Enzymes). Briefly, $160 \mu \mathrm{g} / \mathrm{ml} \mathrm{M} \Phi-\mathrm{NP}$ (MJ) with increasing MJ-33 input was mixed with native bovine PLA2 (600 U/l in PBS) and incubated at $37^{\circ} \mathrm{C}$ for $1 \mathrm{~h}$ before the PLA2 activity was measured. Native bovine PLA2 (600 U/l in PBS) incubated at $37^{\circ} \mathrm{C}$ for $1 \mathrm{~h}$ served as a positive control. PLA2 activity was measured by the EnzChek PLA2 activity assay kit (ThermoFisher Scientific) with a calibration curve measured with PLA2 standards of known enzymatic activity. PLA2 inhibition was calculated by subtracting the PLA2 activity of nanoparticle-PLA2 mixtures from that of the positive control sample. MJ-33 input that resulted in the maximum PLA2 inhibition (16\% of membrane protein weight) was used for subsequent studies.

Fabrication of lure and kill macrophage membrane-coated nanoparticles. To fabricate M $\Phi-\mathrm{NP}(\mathrm{L} \& \mathrm{~K}), 2 \mathrm{mg} / \mathrm{ml} \mathrm{M} \Phi-\mathrm{NP}(\mathrm{MJ})$ was incubated with melittin (5-160 $\mu \mathrm{g} / \mathrm{ml}$, corresponding to $0.25-8 \%$ membrane protein weight, MilliporeSigma) at $37^{\circ} \mathrm{C}$ for $30 \mathrm{~min} . \mathrm{M} \Phi-\mathrm{NP}(\mathrm{L} \& \mathrm{~K})$ were then washed twice with centrifugation. Melittin input into MФ-NP(MJ) was optimized by measuring the inhibitory capacity of the resulting $\mathrm{M} \Phi-\mathrm{NP}(\mathrm{L} \& \mathrm{~K})$ against native bovine PLA2. Briefly, M $\Phi-\mathrm{NP}(\mathrm{L} \& \mathrm{~K})(160 \mu \mathrm{g} / \mathrm{ml})$ with increasing melittin input was mixed with $600 \mathrm{U} / \mathrm{l}$ native bovine PLA2 and incubated at $37^{\circ} \mathrm{C}$ for $1 \mathrm{~h}$. PLA2 activity was measured to calculate PLA2 inhibition by M $\Phi-\mathrm{NP}(\mathrm{L} \& \mathrm{~K})$. PLA2 inhibition was calculated using the same method as mentioned above. The melittin input that resulted in the maximum PLA2 inhibition (4\% of membrane protein weight) was used to prepare $\mathrm{M} \Phi-\mathrm{NP}(\mathrm{L} \& \mathrm{~K})$ for all subsequent studies.

Quantitative analysis of $\mathbf{M J}-\mathbf{3 3}$ loading yield. Freshly prepared MФ-NP(MJ) or $\mathrm{M} \Phi-\mathrm{NP}(\mathrm{L} \& \mathrm{~K})(30 \mu \mathrm{L}, 2 \mathrm{mg} / \mathrm{mL})$ were centrifuged at $25,000 \times g$ for $10 \mathrm{~min}$ and resuspended in $100 \mu \mathrm{L}$ ultrapure water. To extract cell membrane lipids, $200 \mu \mathrm{L}$ methanol was added to the nanoparticle suspensions and the samples were vigorously vortexed for $30 \mathrm{~s}$. Then $400 \mu \mathrm{L}$ chloroform was added and the mixture was shaken at room temperature for $30 \mathrm{~min}$. After that, the samples were centrifuged at $2500 \times g$ for $5 \mathrm{~min}$. The organic solvent at the bottom was collected, dried under nitrogen flow, and reconstituted in $100 \mu \mathrm{L}$ methanol for HR-ESI-MS analysis. MФ$\mathrm{NP}(30 \mu \mathrm{L}, 2 \mathrm{mg} / \mathrm{mL})$ were processed by following the same procedure and served as a control sample. MJ-33 content in the nanoparticle samples was derived from the relative abundance value $(\mathrm{m} / \mathrm{z}=491.3)$ from the nanoparticle sample using the MJ-33 calibration curve. MJ-33 loading yield was calculated as the weight percentage of MJ-33 in the total membrane protein. Results were fitted by using linear regression function in Graphpad Prism 8.

Quantitative analysis of melittin loading yield. Melittin loading into MФ-NP (L\&K) was derived by measuring the hemolytic activity of melittin solution before and after the incubation with the MФ-NP(MJ). To quantify melittin loading into MФ-NP(L\&K), MФ-NP(MJ) (final concentration $2 \mathrm{mg} / \mathrm{ml}$ ) were mixed with melittin (final concentration $10-160 \mu \mathrm{g} / \mathrm{mL}$ ) and incubated at $37^{\circ} \mathrm{C}$ for $30 \mathrm{~min}$. The mixture was diluted $10 \times$ in PBS and added to washed mouse RBCs ( $5 \mathrm{v} / \mathrm{v} \%)$ in PBS and incubated at $37^{\circ} \mathrm{C}$ for $30 \mathrm{~min}$. Afterwards, the RBC suspension was centrifuged at $16,100 \times g$ for $5 \mathrm{~min}$. Then $20 \mu \mathrm{L}$ supernatant was added into $80 \mu \mathrm{L}$ PBS in 96well plates. Hemoglobin absorption was measured at $540 \mathrm{~nm}$. RBCs (5 v/v\%) in PBS were disrupted with sonication and centrifuged at $16,100 \times g$ for $5 \mathrm{~min}$. The supernatant of sonicated RBCs (5 v/v\%) in PBS was taken as $100 \%$ hemolysis, and the supernatant of intact RBCs $(5 \mathrm{v} / \mathrm{v} \%)$ in PBS was taken as $0 \%$ hemolysis. Hemolysis (\%) was defined as $\left(\mathrm{A}_{\text {sample }}-\mathrm{A}_{\text {intact }}\right) /\left(\mathrm{A}_{\text {sonicated }}-\mathrm{A}_{\text {intact }}\right) \times 100 \%$. The remaining melittin concentration after incubation with the nanoparticles was derived from the calibration curve for melittin-induced hemolysis. Melittin loading was calculated as the weight percentage of melittin in total membrane protein. Results were fitted by using non-linear fitting in Graphpad Prism 8.

Physicochemical properties, morphology, and colloidal stability. MФ-NP (L\&K) were measured for hydrodynamic size and surface zeta potential with dynamic light scattering (DLS, ZEN 3600 Zetasizer, Malvern). To examine the intra-particle structure, nanoparticles were stained with uranyl acetate $(0.2 \mathrm{wt} \%)$ and visualized with transmission electron microscopy (TEM, FEI $200 \mathrm{kV}$ Sphera). To study the long-term colloidal stability, MФ-NP(L\&K) suspensions were adjusted to $1 \times$ PBS or $0.5 \times$ FBS, at a final protein concentration of $0.5 \mathrm{mg} / \mathrm{ml}$. Samples were stored at $37^{\circ} \mathrm{C}$ and nanoparticle hydrodynamic size was measured and monitored once a day for 7 consecutive days.

Cytotoxicity evaluation. J774A.1 macrophages were seeded in a 96-well tissue culture plate at a density of $5 \times 10^{4} \mathrm{cells} / \mathrm{ml}$ and cultured overnight. Cells were then added with various concentrations of free MJ-33 or M $\Phi-\mathrm{NP}(\mathrm{L} \& \mathrm{~K})$ with equivalen MJ-33 content. Cells were then cultured for $24 \mathrm{~h}$. Cell viability was assessed by using a CellTiter Cell Proliferation assay (Promega) based on the manufacturer's instruction

Mouse model of mild acute pancreatitis. A mild acute pancreatitis (CAE-AP) mouse model was established by following a published protocol ${ }^{36}$. Briefly, 6-weekold CD-1 female mice were fasted $12 \mathrm{~h}$ before pancreatitis induction and given ad libitum access to water. Mice received intraperitoneal injections of caerulein (VWR) at $50 \mu \mathrm{g} / \mathrm{kg}$ hourly for $8 \mathrm{~h}$ to induce AP.

Inhibition of PLA2 in serum samples from CAE-AP mice and patients. To collect serum from CAE-AP mice, the whole blood of mice was collected with submandibular bleeding into microtubes and allowed to clot at room temperature for $30 \mathrm{~min}$. Samples were then centrifuged at $2000 \times g$ for $6 \mathrm{~min}$ to collect serum from the supernatant. The serum was then lyophilized and reconstituted to $1 / 10$ of its volume (equivalent to a $10 \times$ serum concentration). Serum samples collected from human AP patients were purchased from BioreclamationIVT. Aliquots of samples were stored at $-80^{\circ} \mathrm{C}$ and used within 2 weeks after the collection. In the study, mouse serum samples $(0.1 \times$ final concentration) were mixed with $\mathrm{M} \Phi-\mathrm{NP}(\mathrm{L} \& \mathrm{~K})$ or control formulations (final concentrations ranging from 0.625 to $160 \mu \mathrm{g} / \mathrm{ml}$ ). Samples were incubated at $37^{\circ} \mathrm{C}$ for $1 \mathrm{~h}$ before PLA2 activity was measured. For studies with human serum samples, M $\Phi-\mathrm{NP}(\mathrm{L} \& \mathrm{~K})$ made from the membrane of THP-1 cells were used. In the study, patient serum samples $(0.1 \times$ final concentration) were mixed with $\mathrm{M} \Phi-\mathrm{NP}(\mathrm{L} \& \mathrm{~K})$ or control formulations (final concentrations ranging from 0.016 to $4 \mathrm{mg} / \mathrm{ml}$ ). Samples were incubated at $37^{\circ} \mathrm{C}$ for $1 \mathrm{~h}$ before the PLA2 activity was measured. $\mathrm{IC}_{50}$ values were derived from the variable slope model using Graphpad Prism 8.

Pharmacokinetics and biodistribution assessments. To characterize the pharmacokinetics and biodistribution of MФ-NP(L\&K) in vivo, MФ-NP(L\&K) were prepared from DiR-loaded PLGA cores. To study pharmacokinetics, $200 \mu \mathrm{l}$ of 3 $\mathrm{mg} / \mathrm{ml}$ fluorescently labeled nanoparticles were administered intravenously into 4 week-old CD-1 female mouse. Blood samples were collected by submandibular bleeding at $3 \mathrm{~min}, 30 \mathrm{~min}, 1 \mathrm{~h}, 3 \mathrm{~h}, 7 \mathrm{~h}, 24 \mathrm{~h}, 48 \mathrm{~h}$, and $72 \mathrm{~h}$. Samples were then diluted $10 \times$ with PBS and the fluorescence intensity was measured (Tecan Infinite M200 multiplate reader). Pharmacokinetic parameters were calculated by fitting the curve with a two-compartment model. For the biodistribution study, $200 \mu \mathrm{l}$ of $3 \mathrm{mg} / \mathrm{ml}$ fluorescently labeled nanoparticles were administered intravenously into 4-week-old CD-1 female mice. At 24,48 , and $72 \mathrm{~h}$ after the injection, organs, including the liver, kidneys, spleen, lungs, heart, blood, and pancreas, were collected from a randomly grouped subset of mice. Organs were weighed and then homogenized in PBS with a Mini-Beedbeater-16 (Biospec Products) for fluorescence measurement.

Characterization of in vivo toxicity. To evaluate the toxicity, MФ-NP(L\&K) were injected intravenously $(80 \mathrm{mg} / \mathrm{kg})$ through the tail vein into 4 -week-old CD-1 female mice daily for 4 days. At $24 \mathrm{~h}$ after the last injection, $\sim 250 \mu \mathrm{l}$ of whole blood was collected into Eppendorf tubes and allowed to coagulate. Then the samples were centrifuged at $2000 \times g$ for $6 \mathrm{~min}$ to collect serum for the comprehensive metabolic panel analysis. Meanwhile, $100 \mu$ l of whole blood was collected into an EDTA-coated microtube for the complete blood count. All blood samples were tested at the UCSD Animal Care Program Diagnostic Services Laboratory. Immediately after blood collection, mice were euthanized to collect major organs, including the liver, kidneys, spleen, lungs, heart, and pancreas. Organs were fixed in $10 \%$ formalin (Fisher Scientific), sectioned, and stained with hematoxylin and eosin (H\&E) for histological analysis. Histology slides were imaged with a Hamamatsu NanoZoomer 2.0-HT slide scanning system.

Assessment of NF-KB nuclear translocation in macrophages. J774A.1 macrophages were seeded in Celltreat tissue culture-treated dishes with a glass bottom (Neta Scientific) at a density of $5 \times 10^{4}$ cells/ml and cultured for $24 \mathrm{~h}$. Serum from CAE-AP mice was reconstituted with the culture medium to a final PLA2 activity of $600 \mathrm{U} / \mathrm{l}$. Then, MФ-NP(L\&K) or control nanoparticles were mixed with the culture medium to reach a final concentration of $400 \mu \mathrm{g} / \mathrm{ml}$ (membrane protein). The final volume in each culture dish was adjusted to $500 \mu \mathrm{l}$ using the culture medium. Cells were incubated for $2 \mathrm{~h}$ at $37^{\circ} \mathrm{C}$ and then washed with PBS 3 times. Washed cells were fixed with $10 \%$ formalin for $15 \mathrm{~min}$, then permeabilized and blocked with a PBS solution containing $0.4 \%$ Triton X-100 (Fisher Scientific) and $2 \% \mathrm{BSA}$ for $30 \mathrm{~min}$ at room temperature. Intracellular NF- $\mathrm{kB}$ was probed with 
anti-mouse NF-kB p65 antibody (clone A-8, 1:200 dilution in PBS, Santa Cruz Biotechnology) for $1 \mathrm{~h}$ at room temperature. Cells were then washed twice with PBS and FITC-anti-mouse IgG (1:500 dilution in PBS, Biolegend) was added to the cells for $20 \mathrm{~min}$ at room temperature. Cells were washed twice and stained with $0.1 \mu \mathrm{g} / \mathrm{ml}$ Hoechst 33342 (ThermoFisher Scientific) for $20 \mathrm{~min}$ at room temperature. Fluorescence was visualized using a Leica SP8 confocal microscope. Quantification of NF-kB nuclear translocation was performed by following a published protocol using Image ${ }^{52}$. Briefly, the Hoechst-positive area was used to define the nuclear region of interest (ROI) for each nucleus. NF-kB-positive area encompassing each nuclear ROI was defined as the ROI for a whole cell. NF- $\mathrm{kB}$ signal within a nucleus was measured by the total fluorescence intensity within the nuclear ROI. NF- $\mathrm{kB}$ signal within a whole cell was measured by the total fluorescence intensity within the ROI of a whole cell. Nuclear translocation (\%) was defined as Fluo $_{\text {nuclei }} /$ Fluo $_{\text {whole cell }} \times 100 \%$. One hundred cells were measured individually for each group. Nuclear translocation histograms were fitted with Gaussian non-linear regression by using GraphPad Prism 8.

Measurement of macrophage cytokine production. J774A.1 macrophages were seeded in 96-well tissue culture plates at a density of $8 \times 10^{4} \mathrm{cells} / \mathrm{ml}$ and cultured overnight. Serum from CAE-AP mice was reconstituted with the culture medium to a final PLA2 activity of $600 \mathrm{U} / \mathrm{l}$. Afterward, MФ-NP(L\&K) or control nanoparticles were mixed with the culture medium to reach final concentrations ranging from 3.125 to $400 \mu \mathrm{g} / \mathrm{ml}$ in membrane protein concentration. The final volume in each well was adjusted to $100 \mu \mathrm{l}$ using the culture medium. Cells were incubated for $6 \mathrm{~h}$ at $37^{\circ} \mathrm{C}$ and the culture medium was collected. Concentrations of inflammatory cytokines IL-6, TNF- $\alpha$, and IL- $1 \beta$ in the culture medium was quantified by using the corresponding ELISA kits (Biolegend).

Isolation of pancreatic acini. Six-week-old healthy CD-1 mice were euthanized, and the pancreatic tissues were collected. Minced pancreatic tissues were dispersed in DMEM with Nutrient Mixture F-12 (DMEM/F12, Gibco) supplemented with $1.0 \mathrm{U} / \mathrm{ml}$ collagenase D from Clostridium histolyticum and $0.25 \mathrm{mg} / \mathrm{ml}$ trypsin inhibitor from soybean (both from Roche Diagnostics). The pancreatic tissues were vigorously shaken at $200 \mathrm{rpm}$ for $2 \mathrm{~h}$ at $37^{\circ} \mathrm{C}$. Digested tissue was filtered by using a cell strainer $(100 \mu \mathrm{m}$ pore size, Corning). Pancreatic acini retained by the cell strainer were transferred to a 24 -well tissue culture plate and cultured overnight in DMEM/F12 medium supplemented with 5\% FBS and 1\% penicillin-streptomycin. Non-adherent pancreatic acini were then transferred into a new 48-well tissue culture plate and used immediately, while adherent contaminant cells were discarded.

Pancreatic acinar cell injury assay. Pancreatic acini were suspended in DMEM/ F12 medium at a density of $800 \mathrm{acini} / \mathrm{ml}$, and $100 \mu \mathrm{l}$ pancreatic acini suspension was added to each well of a 48-well tissue culture plate. Serum from CAE-AP mice was first added to the acini suspension to a final PLA2 activity of $600 \mathrm{U} / \mathrm{l}$. MФ-NP ( $\mathrm{L} \& \mathrm{~K})$ or control nanoparticles were then added to the acini suspension to reach final concentrations ranging from 3.125 to $400 \mu \mathrm{g} / \mathrm{ml}$ in membrane protein concentration. The final volume in each culture dish was adjusted to $200 \mu \mathrm{l}$ using the culture medium. Pancreatic acini were cultured for $24 \mathrm{~h}$ and washed three times with PBS. Cell viability was measured by using a CellTiter Cell Proliferation assay (Promega). To study the cell death pathway of PLA2-induced acinar cell injury, serum from CAE-AP mice was added to the acini suspension $(800 \mathrm{acini} / \mathrm{ml}$ in $100 \mu \mathrm{l}$ culture medium) to a final PLA2 activity of $600 \mathrm{U} / \mathrm{l}$. Then, MФ-NP(L\&K) or control nanoparticles were mixed with the acini suspension to reach a final concentration of $400 \mu \mathrm{g} / \mathrm{ml}$ in membrane protein concentration. The final volume in each well was adjusted to $200 \mu \mathrm{l}$ using the culture medium. The mixtures were incubated for $24 \mathrm{~h}$ at $37^{\circ} \mathrm{C}$ and then washed with PBS for 3 times. PACs were then stained with PE-labeled annexin- $\mathrm{V}$ (1:100 dilution, Biolegend) and propidium iodide (1:5000 dilution, Biolegend), and analysed with a Becton Dickinson FACSCanto-II flow cytometer. Results were analysed using FlowJo software.

\section{Choline-deficient diet and DL-ethionine induced acute pancreatitis mouse} model. The mouse model was established by following a published protocol ${ }^{53}$ Briefly, 4-week-old CD-1 female mice were fasted on day 0 and then fed with choline-deficient and DL-ethionine diet (CDE-diet, MP Biomedicals) from days 1 to 3 , followed by normal laboratory diet on day 4 to induce lethal AP. Survival was monitored for 10 days. Throughout the CDE-diet induced acute pancreatitis (CDEAP) studies, mice had access to water ad libitum.

Protocols of efficacy study in CAE-AP and CDE-AP. In CAE-AP, $2 \mathrm{~h}$ after the initial caerulein administration, $200 \mu \mathrm{l}$ of MФ-NP(L\&K) $(40 \mathrm{mg} / \mathrm{kg})$ was administered intravenously through the tail vein. MФ-NP $(40 \mathrm{mg} / \mathrm{kg}), \mathrm{M} \Phi-\mathrm{NP}(\mathrm{mel})$ $(40 \mathrm{mg} / \mathrm{kg}), \mathrm{M} \Phi-\mathrm{NP}(\mathrm{MJ})(40 \mathrm{mg} / \mathrm{kg})$, or $200 \mu \mathrm{l}$ sterile PBS was administered intravenously to mice at the same time as controls. CAE-AP mouse whole blood was collected at $0,2,4,8,24 \mathrm{~h}$ after initial caerulein injection $(\sim 80 \mu \mathrm{l}$ whole blood per mouse per timepoint) with submandibular bleeding into microtubes and allowed to clot at room temperature for $30 \mathrm{~min}$. Samples were then centrifuged at
$2000 \times g$ for $6 \mathrm{~min}$ to collect serum from the supernatant. Serum samples were immediately frozen at $-20^{\circ} \mathrm{C}$ and analysed for PLA2 activity and cytokine concentration within $24 \mathrm{~h}$. All mice were euthanized at $24 \mathrm{~h}$ after initial caerulein injection to collect pancreatic tissues for measurement of pancreatic tissue PLA2 activity and histological analyses. In CDE-AP studies, $200 \mu \mathrm{l}$ of MФ-NP(L\&K) $(80$ $\mathrm{mg} / \mathrm{kg}$ ) was administered intravenously through the tail vein on days 1,2 , and 3 of the studies. MФ-NP ( $80 \mathrm{mg} / \mathrm{kg}), \mathrm{M} \Phi-\mathrm{NP}(\mathrm{mel})(80 \mathrm{mg} / \mathrm{kg}), \mathrm{M} \Phi-\mathrm{NP}(\mathrm{MJ})(80 \mathrm{mg} /$ $\mathrm{kg}$ ), or $200 \mu \mathrm{l}$ sterile PBS was administered intravenously to mice at the same time as controls. The whole blood of CDE-AP mice was collected on days $0,1,2$, and 3 ( $\sim 80 \mu \mathrm{l}$ whole blood per mouse per timepoint). CDE-AP mouse serum samples were derived and stored following the aforementioned procedures. Pancreatic tissues were collected on day 3 of the CDE-AP studies for histological analyses.

Measurement of PLA2 activity and cytokine levels in serum. Serum samples from CAE-AP mice and CDE-AP mice were diluted $5 \times$ in PBS and serum PLA2 activity was quantified by using the EnzChek PLA2 assay kit. Serum cytokine concentrations were measured by using mouse IL- 6 , mouse TNF- $\alpha$, and mouse IL$1 \beta$ ELISA kits. To measure PLA2 activity in CAE-AP mouse pancreatic tissues, freshly collected mouse pancreas samples were homogenized with a MiniBeedbeater-16 (Biospec Products). The homogenate was immediately diluted 10x in PBS and analysed for PLA2 activity. PLA2 activity results were normalized to the weight of pancreatic tissues.

Histological analysis of pancreatic tissues. For histological analyses, CAE-AP mouse and CDE-AP mouse pancreatic tissues were fixed, sectioned, and stained with H\&E. H\&E-stained sections were visualized by a Hamamatsu NanoZoomer 2.0-HT slide scanning system. Histopathological features including edema, necrotic acinar cells, hemorrhage, and $\mathrm{CD} 45^{+}$cell infiltration were studied. To analyze parenchymal edema in the pancreatic tissue in CAE-AP and CDE-AP models, a representative $0.45 \times 0.45 \mathrm{~mm}$ area was selected from each $\mathrm{H} \& \mathrm{E}$-stained pancreatic section. The selected area was scored by a blinded subject who was unaware of the type of treatment administered to the animals. Score $0=$ no edema; $0.5=$ focal expansion of interlobular space; $1=$ diffuse expansion of interlobular space; $1.5=$ focal expansion of intralobular space; 2 = diffuse expansion of intralobular space $2.5=$ focal expansion of inter-acinar space; $3=$ diffuse expansion of inter-acinar space; $3.5=$ focal expansion of intercellular space; $4=$ diffuse expansion of intercellular space. To quantify the necrotic cells in the pancreatic parenchyma in CAE$\mathrm{AP}$ and CDE-AP models, five $0.15 \times 0.15 \mathrm{~mm}$ areas were randomly selected from each H\&E-stained pancreatic section. Necrotic cells in each area were counted. To study the extent of hemorrhage in the CDE-AP model, a representative $0.6 \times 0.6$ $\mathrm{mm}$ area was selected from each pancreatic section. The hemorrhagic area was defined as the area containing extravasated erythrocytes and quantified using Adobe Photoshop. Counts of necrotic acinar cells and hemorrhagic area results were normalized to the area occupied by the pancreatic tissue. To study $\mathrm{CD} 45^{+}$cell infiltration into the pancreas, pancreatic tissues were sectioned and stained with a rabbit anti-mouse CD45 antibody (Abcam, 1:200 dilution). Biotinylated anti-rabbit IgG (Abcam, 1:500 dilution) was used as the secondary antibody for chromagen development. Sections were counter-stained with haematoxylin to visualize cell nuclei and were scanned by a Hamamatsu NanoZoomer 2.0-HT slide scanning system. A $0.15 \times 0.15 \mathrm{~mm}$ area in each anti-CD45-stained pancreatic section was selected to quantify $\mathrm{CD}_{4} 5^{+}$cell infiltration using ImageJ. Briefly, RGB images of anti-CD45-stained pancreatic sections were converted to 16-bit grayscale images. A standard threshold was applied to exclude $\mathrm{CD} 45^{-}$cells. The remaining $\mathrm{CD}^{-} 5^{+}$cells were counted by using ImageJ Particle Analyzer. Counts of $\mathrm{CD}_{4} 5^{+}$cells were normalized to the area occupied by the pancreatic tissue.

Statistical analysis. Statistical analyses of serum biomarkers were performed using a repeated-measure one-way ANOVA with Dunnett's post hoc analysis. Statistical difference in edema scores was analyzed by Kruskal-Wallis nonparametric test with Dunnett's post hoc analysis. Necrotic cell counts, tissue PLA2 activity, and $\mathrm{CD}_{4} 5^{+}$cell counts were analyzed by using one-way ANOVA with Dunnett's post hoc analysis. Animal survival data were analysed by using the logrank (Mantel-Cox) test. In the CAE-AP study, $n=10$ mice in all groups. In CDEAP studies, $n=10$ mice in all groups. Replicates represent different mice subjected to the same treatment.

Reporting summary. Further information on research design is available in the Nature Research Reporting Summary linked to this article.

\section{Data availability}

All data are available within the article, Supplementary Information or available from the corresponding authors upon reasonable request. Source data are provided with this paper.

Received: 16 January 2021; Accepted: 17 June 2021; Published online: 06 July 2021 


\section{References}

1. Lee, P. J. \& Papachristou, G. L. New insights into acute pancreatitis. Nat. Rev. Gastroenterol. Hepatol. 16, 479-496 (2019).

2. Sah, R. P., Garg, P. \& Saluja, A. K. Pathogenic mechanisms of acute pancreatitis. Curr. Opin. Gastroenterol. 28, 507-515 (2012).

3. Afghani, E. et al. Acute pancreatitis-progress and challenges a report on an international symposium. Pancreas 44, 1195-1210 (2015).

4. Bakker, O. J. et al. Treatment options for acute pancreatitis. Nat. Rev. Gastroenterol. Hepatol. 11, 462-469 (2014).

5. Krishna, S. G., Kamboj, A. K., Hart, P. A., Hinton, A. \& Conwell, D. L. The changing epidemiology of acute pancreatitis hospitalizations a decade of trends and the impact of chronic pancreatitis. Pancreas 46, 482-488 (2017).

6. Hackert, T. \& Werner, J. Antioxidant therapy in acute pancreatitis: experimental and clinical evidence. Antioxid. Redox Signal. 15, 2767-2777 (2011).

7. Besselink, M. et al. IAP/APA evidence-based guidelines for the management of acute pancreatitis. Pancreatology 13, E1-E15 (2013).

8. Whitcomb, D. C. Acute pancreatitis. N. Engl. J. Med. 354, 2142-2150 (2006).

9. Saluja, A. K., Lerch, M. M., Phillips, P. A. \& Dudeja, V. Why does pancreatic overstimulation cause pancreatitis? Annu. Rev. Physiol. 69, 249-269 (2007).

10. Al Mofleh, I. A. Severe acute pancreatitis: pathogenetic aspects and prognostic factors. World J. Gastroenterol. 14, 675-684 (2008).

11. Logsdon, C. D. \& Ji, B. A. The role of protein synthesis and digestive enzymes in acinar cell injury. Nat. Rev. Gastroenterol. Hepatol. 10, 362-370 (2013).

12. Murakami, M., Taketomi, Y., Sato, H. \& Yamamoto, K. Secreted phospholipase A(2) revisited. J. Biochem. 150, 233-255 (2011).

13. Browne, G. W. \& Pitchumoni, C. S. Pathophysiology of pulmonary complications of acute pancreatitis. World J. Gastroenterol. 12, 7087-7096 (2006).

14. Elder, A. S. F., Saccone, G. T. P. \& Dixon, D. L. Lung injury in acute pancreatitis: mechanisms underlying augmented secondary injury. Pancreatology 12, 49-56 (2012).

15. Carroll, J. K., Herrick, B., Gipson, T. \& Lee, S. P. Acute pancreatitis: diagnosis, prognosis, and treatment. Am. Fam. Physician 75, 1513-1520 (2007).

16. Tomita, Y. et al. Effect of a selective inhibitor of secretory phospholipase A(2), S-5920/LY315920Na, on experimental acute pancreatitis in rats. J. Pharmacol. Sci. 96, 144-154 (2004).

17. Zhang, K. J., Zhang, D. L., Jiao, X. L. \& Dong, C. Effect of phospholipase A2 silencing on acute experimental pancreatitis. Eur. Rev. Med. Pharmacol. Sci. 17, 3279-3284 (2013).

18. Chen, J., Ye, L., Sun, Y. \& Takada, Y. A concise update on the relevance of secretory phospholipase A2 group IIA and its inhibitors with cancer. Med. Chem. 13, 606-615 (2017).

19. Reid, R. C. Inhibitors of secretory phospholipase A2 group IIA. Curr. Med. Chem. 12, 3011-3026 (2005).

20. Fang, R. H., Kroll, A. V., Gao, W. \& Zhang, L. Cell membrane coating nanotechnology. Adv. Mater. 30, 1706759 (2018).

21. Pang, Z. Q. et al. Detoxification of organophosphate poisoning using nanoparticle bioscavengers. ACS Nano 9, 6450-6458 (2015).

22. Hu, C. M. J., Fang, R. H., Copp, J., Luk, B. T. \& Zhang, L. A biomimetic nanosponge that absorbs pore-forming toxins. Nat. Nanotechnol. 8, 336-340 (2013).

23. Zhang, Q. Z., Fang, R. H., Gao, W. \& Zhang, L. A biomimetic nanoparticle to "lure and kill" phospholipase A2. Angew. Chem. Int. Ed. 59, 10461-10465 (2020).

24. Zhang, Q. Z. et al. Cellular nanosponges inhibit SARS-Cov-2 infectivity. Nano Lett. 20, 5570-5574 (2020).

25. Shrivastava, P. \& Bhatia, M. Essential role of monocytes and macrophages in the progression of acute pancreatitis. World J. Gastroenterol. 16, 3995-4002 (2010).

26. Steiner, M. R., Bomalaski, J. S. \& Clark, M. A. Responses of purified phospholipase-A(2) to phospholipase-A(2) activating protein (PLAP) and melittin. Biochim. Biophys. Acta 1166, 124-130 (1993).

27. Thamphiwatana, S. et al. Macrophage-like nanoparticles concurrently absorbing endotoxins and proinflammatory cytokines for sepsis management. Proc. Natl Acad. Sci. USA. 114, 11488-11493 (2017).

28. $\mathrm{Hu}, \mathrm{C}$. M. et al. Erythrocyte membrane-camouflaged polymeric nanoparticles as a biomimetic delivery platform. Proc. Natl Acad. Sci. USA. 108, 10980-10985 (2011).

29. Blanco, E., Shen, H. \& Ferrari, M. Principles of nanoparticle design for overcoming biological barriers to drug delivery. Nat. Biotechnol. 33, 941-951 (2015).

30. Jakkampudi, A. et al. Nf-kb in acute pancreatitis: Mechanisms and therapeutic potential. Pancreatology 16, 477-488 (2016).

31. Tsukahara, Y., Morisaki, T., Horita, Y., Torisu, M. \& Tanaka, M. Phospholipase $\mathrm{A}(2)$ mediates nitric oxide production by alveolar macrophages and acute lung injury in pancreatitis. Ann. Surg. 229, 385-392 (1999).
32. Kaiser, A. M., Saluja, A. K., Sengupta, A., Saluja, M. \& Steer, M. L. Relationship between severity, necrosis, and apoptosis in 5 models of experimental acute-pancreatitis. Am. J. Physiol. Cell Physiol. 269 C1295-C1304 (1995).

33. Jacob, T. G., Raghav, R., Kumar, A., Garg, P. K. \& Roy, T. S. Duration of injury correlates with necrosis in caerulein-induced experimental acute pancreatitis: Implications for pathophysiology. Int. J. Exp. Pathol. 95, 199-208 (2014).

34. Schmidt, J. et al. Histopathologic correlates of serum amylase activity in acute experimental pancreatitis. Dig. Dis. Sci. 37, 1426-1433 (1992).

35. Makela, A., Kuusi, T., Nuutinen, P. \& Schroder, T. Phospholipase A2 activity in body fluids and pancreatic tissue in patients with acute necrotising pancreatitis. Eur. J. Surg. 165, 35-42 (1999).

36. Ren, Z. et al. A novel derivative of the natural product danshensu suppresses inflammatory responses to alleviate caerulein-induced acute pancreatitis. Front. Immunol. 9, 2513 (2018).

37. Niederau, C., Luthen, R., Niederau, M. C., Grendell, J. H. \& Ferrell, L. D. Acute experimental hemorrhagic-necrotizing pancreatitis induced by feeding a choline-deficient, ethionine-supplemented diet - methodology and standards. Eur. Surg. Res. 24, 40-54 (1992).

38. Cook, N. R. et al. Clinical utility of lipoprotein-associated phospholipase A(2) for cardiovascular disease prediction in a multiethnic cohort of women. Clin. Chem. 58, 1352-1363 (2012).

39. Scott, K. F. et al. Emerging roles for phospholipase A(2) enzymes in cancer. Biochimie 92, 601-610 (2010)

40. Cunningham, T. J. et al. Secreted phospholipase A2 activity in experimental autoimmune encephalomyelitis and multiple sclerosis. J. Neuroinflammation 3, unsp26 (2006).

41. Talmud, P. J. \& Holmes, M. V. Deciphering the causal role of spla2s and lppla2 in coronary heart disease. Arterioscler. Thromb. Vasc. Biol. 35, 2281-2289 (2015).

42. Leslie, C. C. Thematic review series: Phospholipases: Central role in lipid signaling and disease cytosolic phospholipase $\mathrm{A}(2)$ : physiological function and role in disease. J. Lipid Res. 56, 1386-1402 (2015).

43. Fang, R. H. et al. Cancer cell membrane-coated nanoparticles for anticancer vaccination and drug delivery. Nano Lett. 14, 2181-2188 (2014).

44. Wei, X. L. et al. Nanoparticle functionalization with platelet membrane enables multifactored biological targeting and detection of atherosclerosis. ACS Nano 12, 109-116 (2018).

45. Zhang, Q. Z. et al. Neutrophil membrane-coated nanoparticles inhibit synovial inflammation and alleviate joint damage in inflammatory arthritis. Nat. Nanotechnol. 13, 1182-1190 (2018).

46. Kokotou, M. G., Limnios, D., Nikolaou, A., Psarra, A. \& Kokotos, G. Inhibitors of phospholipase $\mathrm{A}(2)$ and their therapeutic potential: an update on patents (2012-2016). Expert Opin. Ther. Pat. 27, 217-225 (2017).

47. Mingarro, I. et al. Activation of bee venom phospholipase A(2) through a peptide-enzyme complex. FEBS Lett. 372, 131-134 (1995).

48. Kelton, W. et al. Reprogramming MHC specificity by CRISPR-Cas9-assisted cassette exchange. Sci. Rep. 7, 45775 (2017)

49. Kang, R., Lotze, M. T., Zeh, H. J., Billiar, T. R. \& Tang, D. L. Cell death and damps in acute pancreatitis. Mol. Med. 20, 466-477 (2014).

50. Novovic, S. et al. Activity of neutrophil elastase reflects the progression of acute pancreatitis. Scand. J. Clin. Lab. Investig. 73, 485-493 (2013).

51. Wan, J. H. et al. The role of neutrophils and neutrophil extracellular traps in acute pancreatitis. Front. Cell Dev. Biol. 8, 565758 (2021).

52. Noursadeghi, M. et al. Quantitative imaging assay for NF- $\kappa B$ nuclear translocation in primary human macrophages. J. Immunol. Methods 329 , 194-200 (2008)

53. Lombardi, B., Estes, L. W. \& Longnecker, D. S. Acute hemorrhagic pancreatitis (massive necrosis) with fat necrosis induced in mice by DL-ethionine fed with a choline-deficient diet. Am. J. Pathol. 79, 465-480 (1975).

\section{Acknowledgements}

This work is supported by the National Science Foundation Grant DMR-1904702 and the Defense Threat Reduction Agency Joint Science and Technology Office for Chemical and Biological Defense under Grant Number HDTRA1-18-1-0014.

\section{Author contributions}

L.Z. conceived and designed the experiments with W.G. and Q.Z. Q.Z, Jul.Z., and Jia.Z performed all experiments. All authors analyzed and discussed the data. Q.Z., R.H.F., W.G., and L.Z. wrote the paper.

\section{Competing interests}

The authors declare no competing interests. 


\section{Additional information}

Supplementary information The online version contains supplementary material available at https://doi.org/10.1038/s41467-021-24447-4.

Correspondence and requests for materials should be addressed to L.Z.

Peer review information Nature Communications thanks the anonymous reviewers for their contribution to the peer review of this work.

Reprints and permission information is available at http://www.nature.com/reprints

Publisher's note Springer Nature remains neutral with regard to jurisdictional claims in published maps and institutional affiliations. (c) (1) Open Access This article is licensed under a Creative Commons Attribution 4.0 International License, which permits use, sharing, adaptation, distribution and reproduction in any medium or format, as long as you give appropriate credit to the original author(s) and the source, provide a link to the Creative Commons license, and indicate if changes were made. The images or other third party material in this article are included in the article's Creative Commons license, unless indicated otherwise in a credit line to the material. If material is not included in the article's Creative Commons license and your intended use is not permitted by statutory regulation or exceeds the permitted use, you will need to obtain permission directly from the copyright holder. To view a copy of this license, visit http://creativecommons.org/ licenses/by/4.0/.

(C) The Author(s) 2021 